\title{
Simulation of the dynamics of nitrogen metabolism in sheep
}

\author{
By A. MAZANOV* AND J. V. NOLAN \\ Department of Biochemistry and Nutrition, Faculty of Rural Science, \\ The University of New England, Armidale, New South Wales 235 I, Australia
}

$$
\text { (Received 1o fune 1975 - Accepted } 21 \text { fuly 1975) }
$$

\footnotetext{
I. The results of isotope tracer studies of the dynamics of nitrogen metabolism in mature sheep were used to construct a seven-pool mathematical model.

2. The model was extended to a nine-pool model, which incorporates lags describing the time taken for the passage of digesta through the gut of sheep.

3. Simulation studies using these models satisfactorily predicted results of independent experiments.

4. The dynamics of $\mathrm{N}$ metabolism in sheep appear to be best approximated by first-order kinetics; that is, many of the important $\mathrm{N}$ transport processes are substantially linear or concentration-dependent.
}

This paper reports the development of a linear, multi-pool model of the dynamics of nitrogen metabolism in sheep. The model has some variable coefficients and time delays. Variable coefficients were required because of the necessary over-simplifications in little-understood aspects of $\mathrm{N}$ metabolism in sheep. Delays were incorporated into the model in order to describe the time taken for digesta to move through the gut.

Experimental results used in both the construction and validation of the model reported here were based on, and therefore strictly applicable to, forage diets. Energy availability is known to be highly correlated with protein intake in sheep consuming dried, forage-based diets. For example, $r^{2}=0.8$ when digestible crude protein (DCP) is correlated with metabolizable energy (ME; $\mathrm{MJ} / \mathrm{kg}$ ) for forage diets fed to ruminants. This value for $r^{2}$ was calculated using values selected from Table I of McDonald, Edwards \& Greenhalgh (1973). Therefore, the ratio, available energy: $\mathrm{N}$ in the material undergoing rumen fermentation was assumed to be constant. Similarly, since only forage diets were considered, essential amino acids and dietary constituents other than $\mathrm{N}$ were assumed to be non-limiting in sheep given these diets.

Flows of $\mathrm{N}$ between biologically important pools in sheep given a range of forage diets were well predicted by the model for a number of studies, both in these laboratories and elsewhere.

THE SEVEN-POOL MODEL

Steady-state model synthesis

A twenty-five-pool flow model of the dynamics of $\mathrm{N}$ metabolism in sheep was proposed by Nolan \& Leng (I972). This model was defined quantitatively by isotope dilution experiments in animals under steady-state conditions (Nolan, 1971).

* Present address: Research School of Biological Sciences, Australian National University, Canberra, ACT 26010, Australia. 
Model synthesis followed the use of a number of different sites of injection of tracer (e.g., see Nolan, Norton \& Leng, 1976), which resulted in a set of sub-models containing only a few pools in each. These sub-models were incorporated into larger, conceptual $\mathrm{N}$ metabolism models that were representative of the movement of $\mathrm{N}$ in 'whole' sheep (cf. Nolan, 1971; Nolan \& Leng, 1972).

While some of the flows of $\mathrm{N}$ were quantified in these models, many of the $\mathrm{N}$ transfers were not available. Consequently, the model proposed by Nolan \& Leng (1972; Fig. 6) was condensed by treating the post-rumen pools in the 'gut' sequence and also the pools in the 'body fluids' portion of the model, as well as the 'tissue components' in the twenty-five-pool model, as three single pools of $\mathrm{N}$.

Fig. I shows the structure of the resulting seven-pool model in which the 'lower gut' represents all the gut pools shown below the rumen microbial $N$ pool in the twentyfive-pool flow model of Nolan \& Leng (1972). In the seven-pool model, the 'undigested plant N' of the Nolan \& Leng (1972) model was assumed to flow directly from pool I, the 'available' $\mathrm{N}$ pool in the rumen (Fig. $\mathrm{I}$ ), into the lower gut (pool 5). Pools 2, 3 and 4 correspond respectively to the amino acid- $\mathrm{N}$, ammonia- $\mathrm{N}$ and microbial $\mathrm{N}$ pools in the rumen. The body fluids and body tissue $\mathrm{N}$ pools become pools 6 and 7 respectively in the model shown in Fig. $I$.

Even in this simplified model, some of the $\mathrm{N}$ flows were not known for sheep given a 'high- $\mathrm{N}$ ' diet of $800 \mathrm{~g}$ lucerne chaff (containing $23.4 \mathrm{~g} \mathrm{~N}$ )/d. Therefore, estimated flows of $\mathrm{N}$ which made the seven-pool model conform to the assumption of steadystate were used. That is, the sum of the amounts of $\mathrm{N}$ flowing daily into any pool was made exactly equal to the total $\mathrm{N}$ flowing out of that pool; this was also done for the model as a whole. Therefore, when both 'cell sloughings' and the result of 'nitrogenous base' flows from 'tissue components' (Nolan \& Leng, 1972; Fig. 6) were each assumed to be $0.1 \mathrm{~g} \mathrm{~N} / \mathrm{d}$, the transfer of $\mathrm{N}$ from the lower gut to body fluids became $5.6 \mathrm{~g} \mathrm{~N} / \mathrm{d}$ while the flow of $\mathrm{N}$ from rumen fluid $\mathrm{NH}_{3}$ to the tissue pool became $\mathrm{r} \cdot 2 \mathrm{~g} \mathrm{~N} / \mathrm{d}$ to "balance' each pool (Table $\mathrm{I}$ ) in this seven-pool model. The interaction between 'body fluids amino acid- $\mathrm{N}$ ' and 'intracellular amino acid- $\mathrm{N}$ ' was assumed to consist of equal and opposite flows of $\mathrm{N}$; these two pathways were, erroneously, omitted in prototype models of the dynamics of $\mathrm{N}$ metabolism in sheep.

A similar seven-pool model was constructed for sheep given a diet of $(\mathrm{g} / \mathrm{d}) 500$ wheaten chaff, 10o Solka floc, 20 dried molasses. This diet provided an average intake of $4.9 \mathrm{~g} \mathrm{~N} / \mathrm{d}$ but, for precise model balance, the input and the sum of losses were both assumed to be $4.9 \mathrm{I} \mathrm{g} \mathrm{N} / \mathrm{d}$ in the model for the 'low- $\mathrm{N}$ ' diet. Identical pathways to those used in the 'high- $\mathrm{N}$ ' model were assumed for the 'low- $\mathrm{N}$ ' model and $\mathrm{N}$ flows were estimated by incorporating the results reported in Nolan (1971) and by subsequently balancing the flows to and from each pool, as well as for the whole model (Table 2).

The final, mean, seven-pool model that was assumed to be characteristic of the dynamics of $\mathrm{N}$ metabolism in sheep consuming forage diets containing between 4.9 and $23.4 \mathrm{~g} \mathrm{~N} / \mathrm{d}$ is shown in Fig. I. The flows shown in Fig. I are simply the average of the 'high- $\mathrm{N}$ ' and 'low- $\mathrm{N}$ ' balanced model flows shown in Tables $\mathrm{I}$ and 2 respectively. Obviously, the average model must also be in steady-state with the input and the sum of the losses of $\mathrm{N}$ exactly equal to $14 \cdot 155 \mathrm{~g} \mathrm{~N} / \mathrm{d}$. 


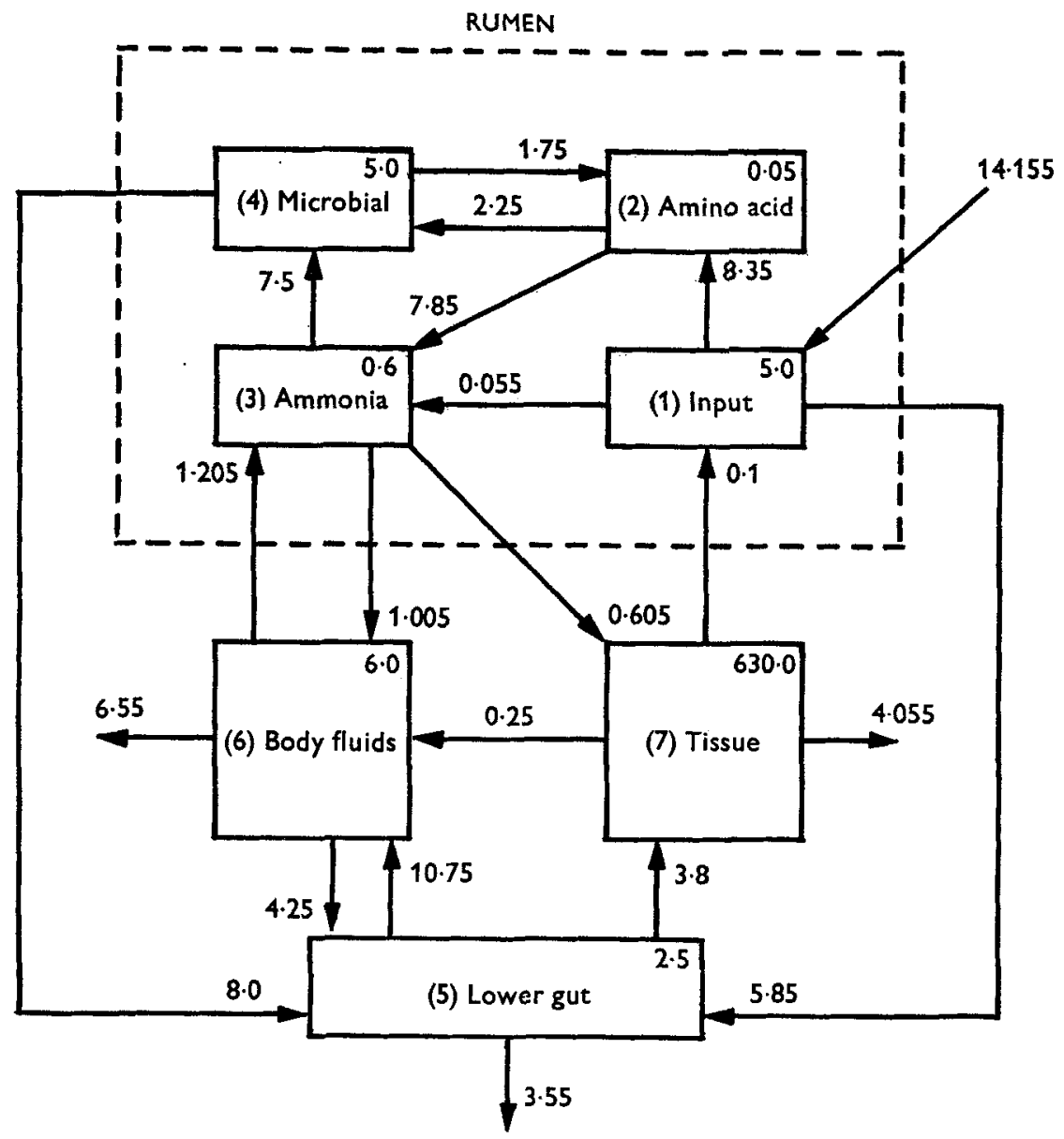

Fig. r. Seven-pool model of the dynamics of nitrogen metabolism in sheep consuming forage diets, with values for $N$ transfers $(\mathrm{g} \mathrm{N} / \mathrm{d}$ ) shown for a dietary $\mathrm{N}$ intake of $14 \cdot 155 \mathrm{~g} \mathrm{~N} / \mathrm{d}$. The value $(g N)$ in the top right-hand corner of each box represents the steady-state pool size for the average dietary $N$ intake corresponding to the $N$ flows given.

The contents of each of the rumen pools were estimated from measurements of rumen volume, which were multiplied by estimates of concentrations of metabolites and the proportion of dry matter in rumen contents samples. Body fluid space was estimated from the live weights of sheep (cf. Packett \& Groves, 1965), used in conjunction with probable plasma protein and measured plasma urea concentrations. Body tissue protein mass was estimated by assuming that carcass compositions of sheep consuming the 'high- $\mathrm{N}$ ' and 'low- $\mathrm{N}$ ' diets were similar to those reported by Panaretto $(1963)$.

The remaining numerical estimates were obtained from a wide range of sources in the published literature. Estimates of all pool sizes were made independently for each of the two experimental diets and also for the 'average' diet. They appeared to be generally consistent with values obtained experimentally in our laboratories.

The seven-pool model structure for the 'whole animal' constitutes the minimum 
Table 1. 'High-nitrogen' model flows $(\mathrm{g} N / d)$ from donor pool $\mathrm{j}$ to acceptor pool i between the pools shown in the seven-pool model of the dynamics of $N$ metabolism in sheep consuming forage diets in Fig. I*

\begin{tabular}{|c|c|c|c|c|c|c|c|c|}
\hline \multirow{2}{*}{\multicolumn{2}{|c|}{$\begin{array}{l}\text { Steady-state pool } \\
\text { size }(\mathrm{gN})\end{array}$}} & \multicolumn{6}{|c|}{ (Values not included are 0.0 ) } & \multirow[b]{2}{*}{$700 \cdot 0$} \\
\hline & & $4 \cdot 0$ & 0.08 & $1 \cdot 0$ & $8 \cdot 0$ & 4.0 & $10 \cdot 0$ & \\
\hline .. & & $\mathbf{I}$ & 2 & 3 & 4 & 5 & 6 & 7 \\
\hline \multicolumn{9}{|c|}{ Input $(\mathrm{g} \mathrm{N} / \mathrm{d}) \quad i$} \\
\hline \multirow{7}{*}{$23 \cdot 4$} & $\mathbf{I}$ & -23.5 & . & . & · & . & . & $0 \cdot 1$ \\
\hline & 2 & I3.9 & $-17 \cdot 0$ & • & $3 \cdot 1$ & - & $\cdot$ & $\cdot$ \\
\hline & 3 & $0 \cdot 1$ & $12 \cdot 9$ & $-14 \cdot 2$ & $\cdot$ & . & $I \cdot 2$ & - \\
\hline & 4 & . & $4 \cdot 1$ & II O & $-15 \cdot 1$ & 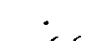 & . & . \\
\hline & 5 & 9.5 & $\cdot$ & $\cdot$ & I $2 \cdot 0$ & $-26 \cdot 6$ & $5 \cdot r$ & $\cdot$ \\
\hline & 6 & . & . & $2 \cdot 0$ & · & $16 \cdot 3$ & $-18 \cdot 4$ & 0.1 \\
\hline & 7 & . & . & $1 \cdot 2$ & . & $5^{\cdot 6}$ & . & -6.8 \\
\hline Losses (g N/d) & & . & . & . & . & $4 \cdot 7$ & $12 \cdot I$ & $6 \cdot 6$ \\
\hline
\end{tabular}

* For details of model dynamics, see p. 153 .

Table 2. 'Low-nitrogen' model flows $(\mathrm{g} N / \mathrm{d})$ from donor pool $\mathrm{j}$ to acceptor pool $\mathrm{i}$ between the pools shown in the seven-pool model of the dynamics of $N$ metabolism in sheep consuming forage diets in Fig. I*

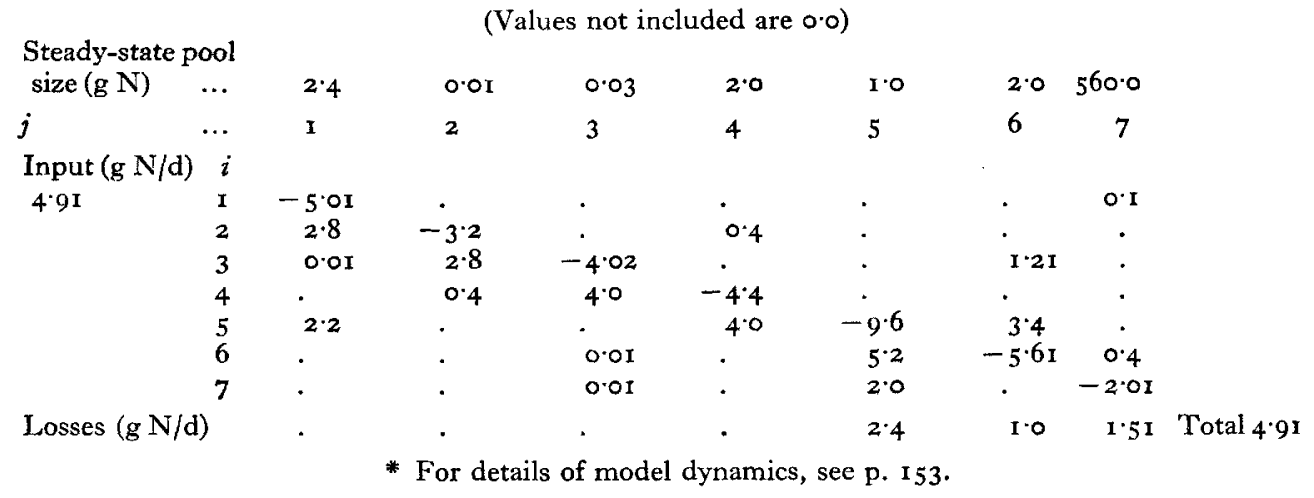

system of interconnected pools of $\mathrm{N}$ that can be validated by comparing model behaviour with the dynamics of $\mathrm{N}$ metabolism in sheep. It is also the largest model that could readily be constructed from the results reported by Nolan (197I) and Nolan \& Leng (1972).

\section{General theoretical considerations}

The change in the concentration of an isotope tracer in a set of kinetic 'components' can best be described by first-order kinetics, and therefore can be fitted by equations which are sums of exponential terms (Berman \& Schoenfeld, I956; Rescigno \& Segre, I966; Shipley \& Clarke, 1972). The coefficients and exponents of the resulting equations can be used to estimate pool sizes and rates of flow of metabolites through the pools that are sampled (Nolan \& Leng, 1972 ). In practice, results from isotope dilution experiments with animals are usually well fitted by curves with two, three or four exponential terms. This indicates the number of 'recognizable' compartments in the system even though a large number of dynamic compartments is involved. 
Any finite part of a continuous, real-valued function can be approximated by the sum of a finite number of exponential functions with real exponents and coefficients. The number of terms needed depends only on the assigned precision (Muntz, I936). Since each exponential term used to fit experimental data implies a separate compartment, a minimum number of these exponential components should be used to fit a given set of biological data (Berman, 1963, 1969; Mancini \& Pilo, 1970).

For example, an artificial set of data with small random errors and a large number of points could be fitted progressively more accurately by using an increasing number of exponential terms in the equation to the fitted curve. A fit using more than three or four exponential terms may reflect only the imprecision of a set of experimental data points and also the finiteness of the time interval. In addition, because mixing of tracer cannot be instantaneous, care must be taken to minimize the number of exponential terms in the equation to the fitted curve.

\section{Model dynamics}

If first-order kinetics are assumed for the flow of $\mathrm{N}$ between all pools in the sevenpool model, then any flow, $r_{i j}$, of tracer or tracee (unlabelled material) out of pool $j$ will be proportional to the size, $q_{j}$, of that pool. In a steady-state system the inputs of $\mathrm{N}, f_{j}$, are zero or constant for each pool $j$, with at least one $f_{j}$ value non-zero. The constant of proportionality, $k_{i j}$, that describes the first-order kinetic flow from the donor pool, $j$, to the acceptor pool, $i$, is the ratio, $r_{i j}: q_{j}$ (the quantity of $\mathrm{N}$ transferred: the steady-state size of the source pool). Total loss rate of $\mathrm{N}$ from pool $j, k_{j j}$, is the sum of all the quantities of $\mathrm{N}$ flowing out of pool $j$ divided by $q_{j}$ and this result is negative.

When the rate of input of $\mathrm{N}$ into pool $\mathrm{I}$ of the average seven-pool model (Fig. $\mathrm{I}$ ) is suddenly changed to a new constant input, $f_{1}$, the subsequent rate of change,

$$
\frac{d q_{i}(t)}{d t} \equiv \dot{q}_{i}(t)
$$

in the size of each of the seven pools in the system will be:

$$
\begin{aligned}
& \dot{q}_{1}(t)=-\frac{(8.35+0.055+5.85)}{5 \cdot 0} q_{1}(t)+\frac{0.1}{630.0} q_{7}(t)+f_{1}(t), \\
& \dot{q}_{2}(t)=\frac{8 \cdot 35}{5 \cdot 0} q_{1}(t)-\frac{(7 \cdot 85+2 \cdot 25)}{0 \cdot 05} q_{2}(t)+\frac{\mathrm{r} \cdot 75}{5 \cdot 0} q_{4}(t), \\
& \dot{q}_{3}(t)=\frac{0.055}{5.0} q_{1}(t)+\frac{7.85}{0.05} q_{2}(t)-\frac{(7.5+\mathrm{I} \cdot 005+0.605)}{0.6} q_{3}(t)+\frac{\mathrm{I} \cdot 205}{6.0} q_{6}(t), \\
& \dot{q}_{4}(t)=\frac{2 \cdot 25}{0.05} q_{2}(t)+\frac{7 \cdot 5}{0.6} q_{3}(t)-\frac{(\mathrm{I} \cdot 75+8 \cdot 0)}{5 \cdot 0} q_{4}(t), \\
& \dot{q}_{5}(t)=\frac{5 \cdot 85}{5 \cdot 0} q_{1}(t)+\frac{8 \cdot 0}{5 \cdot 0} q_{4}(t)-\frac{(10 \cdot 75+3 \cdot 8+3 \cdot 55)}{2 \cdot 5} q_{5}(t)+\frac{4 \cdot 25}{6 \cdot 0} q_{6}(t), \\
& \dot{q}_{6}(t)=\frac{\mathrm{r} \cdot 005}{0.6} q_{3}(t)+\frac{10 \cdot 75}{2 \cdot 5} q_{5}(t)-\frac{(\mathrm{x} \cdot 205+4 \cdot 25+6.55)}{6 \cdot 0} q_{6}(t)+\frac{0.25}{630 \cdot 0} q_{7}(t) \text {, } \\
& \dot{q}_{7}(t)=\frac{0.605}{0.6} q_{3}(t)+\frac{3 \cdot 8}{2 \cdot 5} q_{5}(t)-\frac{(0.1+0.25+4 \cdot 055)}{630 \cdot 0} q_{7}(t),
\end{aligned}
$$


Table 3. The matrix of coefficients $\mathrm{k}_{\mathrm{ij}}$ (the constant of proportionality that describes the first-order kinetics from the donor pool, $j$, to the acceptor pool, i) for the seven-pool model of the dynamics of nitrogen metabolism in sheep consuming forage diets shown in Fig. I and used in equation 3 ( $\left.p .1_{54}\right)$

(The roots of the resulting characteristic polynomial of equation 3 are given below the matrix. Identifiers $i$ and $j$ of $k_{i j}$ in equation 3 refer to rows and columns respectively)

$\begin{array}{lrc}-2.851 & 0 & 0 \\ 1.67 & -202 & 0 \\ 0.011 & 157 & -15.183 \\ 0 & 45 & 12.5 \\ 1 \cdot 17 & 0 & 0 \\ 0 & 0 & 1.675 \\ 0 & 0 & 1.008 \\ -2.852 & -202.1 & -15.77\end{array}$

$\begin{array}{cccl}r \text { Matrix } & & & \\ 0 & 0 & 0 & 0.000 \mathrm{r} 587 \\ 0.35 & 0 & 0 & 0 \\ 0 & 0 & 0.20083 & 0 \\ -\mathrm{I} \cdot 95 & 0 & 0 & 0 \\ \mathbf{I} \cdot 6 & -7.24 & 0.7083 & 0 \\ 0 & 4.3 & -2.0083 & 0.0003968 \\ 0 & \mathrm{I} \cdot 52 & 0 & -0.006992 \\ \text { Roots of polynomial } & & \\ -\mathrm{I} \cdot 394 & -7.769 & -\mathrm{I} \cdot 394 & -0.00683 \\ +0.214 i & & -0.214 i & \end{array}$

with $q_{1}(0)=5 \cdot 0, \quad q_{2}(0)=0.05, \quad q_{3}(0)=0.6, \quad q_{4}(0)=5 \cdot 0, \quad q_{5}(0)=2.5, \quad q_{6}(0)=6 \cdot 0$, $q_{7}(0)=630 \cdot 0$. Actual numerical values from Fig. $\mathrm{I}$ are included to indicate the precise relationship between the mathematical model as defined by equation series $I$ and the corresponding flow model shown in Fig. I. In general terms, for $n$ pools, equation series I can be rewritten as:

or, in matrix notation,

$$
\dot{q}_{i}(t)=\sum_{j=i}^{n} k_{i j} q_{j}(t)+f_{i}(t) \quad(i=1,2, \ldots, n),
$$

$$
\dot{Q}(t)=K Q(t)+F(t)
$$

where $Q(t)$ and $F(t)$ are column vectors of $n$ quantities $q_{i}(t)$ and $f_{i}(t)$ respectively, and $K$ is the $n \times n$ matrix of coefficients $k_{i j}$ (see Berman \& Schoenfeld, 1956).

Table 3 gives $K$ corresponding to the model in Fig. $\mathrm{I}$, as defined by equation series $\mathrm{I}$. The characteristic polynomial (Wylie, 1966) of this matrix is:

$$
\begin{aligned}
& p^{7}+23 \mathrm{I} \cdot 24 p^{6}+6 \mathrm{I} 62 \cdot 87 p^{5}+54567 \cdot 89 p^{4}+\mathrm{I} 898 \mathrm{I} \mathrm{I} \cdot 0 \mathrm{x} p^{3}+275 \mathrm{I} 4 \mathrm{I} \cdot 89 p^{2}+\mathrm{I} 42365 \cdot 7 p \\
& +959^{\circ} 648 \text {. }
\end{aligned}
$$

The roots of this polynomial are given below the matrix in Table 3 since they are the eigenvalues, $\lambda_{i}$, of this matrix.

Thus, the solution to equation series I can be written as:

$$
\begin{aligned}
q_{i}(t)=\alpha_{i 0}+\alpha_{i 1} e^{-2 \cdot 852}+\alpha_{i 2} e^{-202 \cdot 1}+\alpha_{i 3} e^{-15 \cdot 77 t}+\alpha_{i 1} e^{-7 \cdot 769 t}+\alpha_{i 5} e^{-0.00683 t} & \\
& +\beta_{i} e^{-1 \cdot 39 t} \times \sin (0 \cdot 214 t)+\gamma_{i} e^{-1 \cdot 39 t} \cos (0 \cdot 214 t) \quad(i=1,2, \ldots, 7),
\end{aligned}
$$

where the coefficients $\alpha_{i 0}, \ldots, \alpha_{i 5}, \beta_{i}$ and $\gamma_{i}$ are constants which depend only on initial pool sizes and $f_{1}$ (the constant rate of input of $N$ into the seven-pool model). The period of the oscillations due to the last two terms in equation series 5 is $29.37 \mathrm{~d}$, which means that detection of fluctuations in any solution to equation series 1 would be highly improbable since $\beta_{i} e^{-1 \cdot 39 \times 29 \cdot 37}<2 \beta_{i} \times 10^{-18}$.

Thus, analytical or exact solutions to equation series I can be written down (at the 
expense of much labour) for any given set of initial conditions, $q_{i}(0)$, and constant inputs, $f_{i}$. However, with varying $N$ inputs $f_{i}(t)$ numerical solutions have to be generated to study the dynamics of the linear model given by equation series $I$.

\section{Model stability}

\section{Methods: some problems in analysis}

Since the matrix in Table 3 has a dominant main diagonal whose entries are all negative, while all the off-diagonal entries are positive or zero, equation series $\mathrm{I}$ is stable with respect to perturbations from steady-state (cf. Hearon, I 963). Stability is clearly indicated, in this instance, by the fact that the eigenvalues, $\lambda_{i}$, given in Table 3 , all have negative real parts. Table 3 also suggests that the eigenvalues of such diagonaldominant matrices may be approximated by the entries on the main diagonal of the matrix. Both sets of values for the matrix in Table 3 can be seen to span six orders of magnitude. Such linear multi-compartmental models with constant coefficients can also be shown to be stable independently of any time delay in the transfer of material from one pool to another (Mazanov, 1976).

Differential equation series I are 'stiff' since the smallest eigenvalue of $K$, the coefficient matrix, is less than $-200 \cdot 0$. Consequently, numerical instability of digital computer solutions could arise from discretization errors that would inevitably be present in any finite precision numerical technique that could be used to solve 'stiff' systems of differential equations such as equation series $\mathrm{r}$. Therefore, the stability properties of error propagation in a range of numerical solution techniques should be studied in detail before a particular procedure is selected as suitable.

\section{Numerical method stability}

Examination of the numerical stability of different numerical integration techniques varies in difficulty. Implicit methods such as, for example, the modified Hamming (cf. Ralston, r960) predictor-corrector integration technique are more difficult to examine than single-step methods. Also, although single-step, implicit methods are stable when every product, $h \lambda_{i}$, of integration step-length, $h$, and eigenvalue, $\lambda_{i}$, lies outside the unit circle, in the complex plane and with centre unity, 'it is important to choose a suitable (sic) iteration' procedure (Cooper, 1969).

However, by using the classical formulas of Runge (1895) to solve equation:

$$
\dot{y}=\lambda(y-\alpha),
$$

numerically with $y_{0}=\alpha+\epsilon_{0}$ and step-length $h$, the error after $m$ steps can be found directly. Substitution into the formulas:

$$
\left.\begin{array}{rl}
k_{1} & =h \lambda\left(y_{i}-\alpha\right), \\
k_{2} & =h \lambda\left(y_{i}-\alpha+0.5 k_{1}\right), \\
k_{3} & =h \lambda\left(y_{i}-\alpha+0.5 k_{2}\right), \\
k_{4} & =h \lambda\left(y_{i}-\alpha+k_{3}\right), \\
y_{i+1} & =y_{i}+\frac{\left(k_{1}+2 k_{2}+2 k_{3}+k_{4}\right)}{6},
\end{array}\right\}
$$


gives the error $\epsilon_{m}=y_{m}-y\left(t_{m}\right)$ after $m$ steps, $i=0,1,2, \ldots, m$. Since $y(t)=a$, this error is:

where $\phi$ turns out to be

$$
\epsilon_{m}=\epsilon_{0} \phi^{m}
$$

$$
\phi \equiv\left(\mathrm{x}+h \lambda+\frac{(h \lambda)^{2}}{2}+\frac{(h \lambda)^{3}}{6}+\frac{(h \lambda)^{4}}{24}\right) .
$$

'This analysis gives the 'non-asymptotic' (cf. Cooper, 1969) stability condition: $-2 \cdot 7^{8} 5293<h \lambda<0$, since $-\mathrm{I}<\phi<0$ ensures that $\epsilon_{m}$ decreases as $m$ increases.

Consequently, the method chosen to generate numerical solutions to equation series I and all the other models reported below, was a fourth-order Runge-Kutta procedure as modified by Gill (195I). This method gives the highest possible accuracy by controlling round-off errors in the Runge-Kutta procedure. It requires a minimum number of storage registers and comparatively few instructions (Romanelli, 1960). Also, since Runge-Kutta methods are self-starting, the interval between steps may be changed at will, as can the inputs, $f_{i}$. These methods are comparable in accuracy to predictorcorrector methods (Ralston, 1965 ) and, for fixed-step integration, they are nearly as fast as the modified Hamming technique.

The above considerations ensure that when $-2 \cdot 78<h \lambda_{2}<$ o for equation series $\mathrm{I}$, discretization error propagation in the modified Runge-Kutta method used here will be controlled for all numerical solutions of equation series I and similar mathematical models. Round-off errors are minimized in this method and can usually be ignored (Ralston, I965). Thus truncation errors committed at each step should be used to control numerical integration step size selection.

Truncation error can be estimated in this fourth-order numerical method by comparing solutions $q_{i}^{(h)}$ and $q_{i}^{(0 \cdot 5 h)}$ found each time $t+h$ with step $h$ and two steps, $0.5 h$, respectively. The estimated truncation error, $\epsilon$, which compares favourably with true error, can be calculated as follows:

$$
\hat{\epsilon}=\frac{\mathbf{I}}{\mathrm{I} 5} \sum_{i=1}^{n} w_{i}\left|q_{i}^{(0 \cdot 5 h)}-q_{i}^{(h)}\right|,
$$

where the $w_{i}$ are statistical weights that compensate for the possibility of large differences between pool sizes, $q_{i}$. Of course $\Sigma w_{i}$ should always be unity. For example, in generating numerical solutions to a particular system of two differential equations (for which the exact solutions were known), the actual and estimated truncation errors were found to be $-13.7 \times 10^{-7}$ and $-13.5 \times 10^{-7}$ respectively (see Romanelli, 1960). For equation series $\mathrm{I}$ with pool sizes near steady-state, estimated truncation errors given by equation 9 were $(2 \cdot 0 \pm 0.7) \times 10^{-7}$ when the maximum possible step-length that still ensured numerically stable solutions was used (cf. truncation errors of $(2 \cdot 0 \pm 0.8) \times 10^{-5}$ for the Hamming method solution of the same problem).

The FORTRAN subroutine that was consequently selected to generate all numerical solutions in this study was an IBM 'System $/ 360$ Scientific Subroutine Package' implementation of a variable-step version of the Gill-modified Runge-Kutta scheme (see Romanelli, 1960). This implementation proved to be the most versatile, convenient 
and stable numerical integration technique considered, although solutions using this method took half as long again as a fixed-step Runge-Kutta scheme.

Truncation error was readily monitored in the method used here to solve the 'stiff' differential equations arising from the modelling project reported in this paper. Integration step-length was quickly estimated from the entries on the main diagonal of $K$, the coefficient matrix, for any given simulation model. (In any instance, the step-length was automatically reduced whenever truncation errors became too large, during the computation of numerical solutions to a particular set of differential equations.)

Finally, the self-starting nature of this single-step method made it ideally suited to studies of model responses to step and delta function inputs that were used to simulate tracer-kinetic and other experiments. This final consideration became all the more critical in later studies, when more detailed models included the effect of the rate of passage of digesta in sheep.

\section{Variable-coefficient models}

An appropriate choice of $f_{i}(t)$ and initial conditions in equation series I could be used to reproduce some of the tracer concentration curves that were used to calculate various $\mathrm{N}$ flows in the model (Fig. $\mathrm{I}$ ). Such simulations do not validate the model unless the same model can also simulate the results of a number of different experiments under the same conditions but using a number of different sites of injection of tracer (Berman, 1963). The model would then be validated for that set of constant conditions.

In an $n$-compartment system, the solution to equation 3 with $F(t) \equiv 0$ is:

$$
q_{i}(t)=\sum_{j=1}^{n} \eta_{i j} e^{\lambda_{j} t} \quad(i=1,2,3, \ldots, n)
$$

where $\eta_{i j}$ are constants and the eigenvalues $\lambda_{j}$, of $K$ are distinct (Benyon, I968) with negative real parts (Hearon, 1963; Mazanov, 1976). With only one of the $q_{i}(0)$ non-zero, equation series ro could be used to simulate 'single-injection' tracer experiments. When $F$ is a constant non-zero vector and $Q(0)$ is a zero vector, the solution to equation 3 is:

$$
q_{i}(t)=\sum_{j=1}^{n} u_{i j}\left(\mathrm{I}-e^{\lambda_{j} t}\right) \quad(i=\mathrm{I}, 2,3, \ldots, n),
$$

where the $u_{i j}$ are constants and the $\lambda_{j}$ are the same as for equation series Io. This instance could be used to simulate 'continuous-infusion' tracer experiments. Clearly, when each of the constant inputs of tracer, $f_{i}$, into the system is halved, the plateau concentrations of tracer in every pool in the system will eventually halve in a system which stays in steady-state.

A consequence of the linearity of the model equation series $\mathrm{I}$ is that the steady-state pool sizes, $q_{i}(\infty)$, in the system must halve or double if each and every constant input, $f_{i}$, of $\mathrm{N}$ is halved or doubled.

Table 4 gives the quantities of $\mathrm{N}$ in each of the seven pools (Fig. I) for the constant-coefficient (Table 3) model, together with values predicted by the assumption of linearity and those expected on biological premises. Comparison of the biologically expected pool sizes for animals consuming diets on which the model was based with 
Table 4. The seven-pool model of the dynamics of nitrogen metabolism in sheep consuming forage diets: predicted $(P)$ (by model shown in Fig. I using matrix given in Table 3) and expected $(E)$ pool sizes $(g N)$ at time infinity

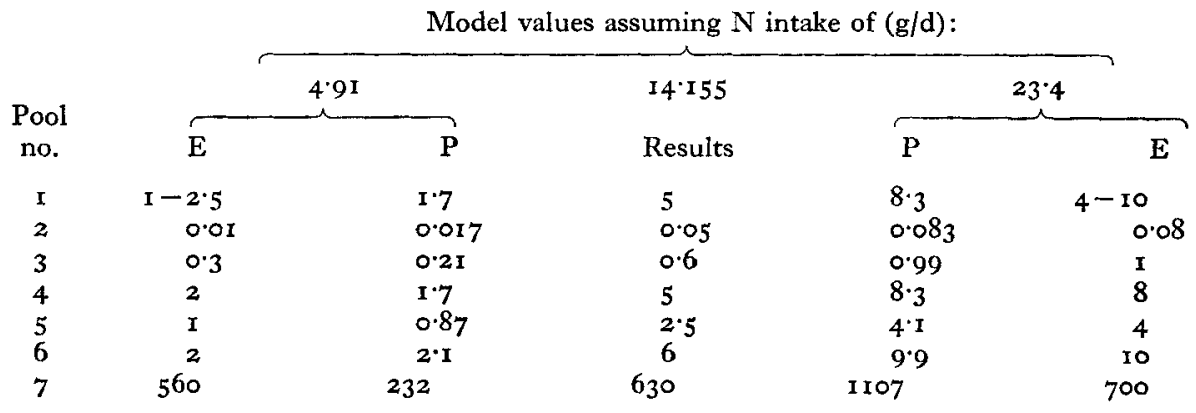

the quantities of $\mathrm{N}$ in pools $\mathrm{I}-6$ that were predicted shows close agreement. The size of pool 7 was not well predicted by this model since the tissue mass of sheep does not halve or double as dietary $\mathrm{N}$ intake halves or doubles (Panaretto, I963).

Thus, either a more complex constant-coefficient model or a variable-coefficient model must be constructed. In other words, some of the $k_{i j}$ in equation series 2 or equation 3 must be variable because in the seven-pool model, the various components of tissue $\mathrm{N}$ are considered to be a single, homogeneous pool. This is a gross over-simplification made in the absence of more (adequate) biological data.

However, wool growth and presumably other integumental growth rates respond quickly to protein or amino acid availability (Downes, Reis, Sharry \& Tunks, 1970) and these could be related to dietary $N$ intake. The loss of $\mathrm{N}$ from the tissue pool, for example, and the quantity of $\mathrm{N}$ recycled to pools $\mathrm{I}$ and 6 may be functions of dietary $\mathrm{N}$ input, $f_{1}(t)$. Making the rate-coefficients associated with these three transfers of $\mathrm{N}$ functions of $f_{1}(t)$ would not make the model (Fig. I) non-linear, since none of the coefficients would become a function of any of the pool sizes of the model.

Pool 7 can be constrained to a linear interpolation between the expected $\mathrm{N}$ content of the tissue pool for ' low- $\mathrm{N}$ ' and 'high-N' models, without disturbing the balance of the first six pools of the model in Fig. I. This result can be achieved by relating the entries in the last column of Table 3 to the daily rate of dietary $\mathrm{N}$ intake, for instance, by the following relationships:

where

$$
\left.\begin{array}{l}
k_{77}=-\frac{4.405}{\xi}, \\
k_{17}=\frac{0.1}{\xi}, \\
k_{67}=\frac{0.25}{}
\end{array}\right\}
$$

$$
\xi=107 \cdot 2+\frac{7400 \cdot 6}{\int_{t-R}^{t} f_{1}(\tau) d \tau} \text { with } \int_{t-R}^{t} f_{1}(\tau) d \tau \geqslant 2 \cdot 0
$$


Table 5. The seven-pool model of the dynamics of nitrogen metabolism in sheep consuming forage diets (equation $3(p .154)$ with the matrix in Table 3 modified by equation series $12(p .158))$ : calculations from predicted pool sizes compared with values reported by Cocimano $\mathbb{E}^{\circ}$ Leng (1967)

\begin{tabular}{|c|c|c|c|c|c|c|c|c|c|}
\hline \multirow[b]{2}{*}{ Diet* } & \multirow{2}{*}{$\begin{array}{l}\text { Intake } \\
(\mathrm{g} \mathrm{N} / \mathrm{d})\end{array}$} & \multicolumn{2}{|c|}{$\begin{array}{l}\text { Body-wt } \\
\text { (kg) }\end{array}$} & \multicolumn{2}{|c|}{$\begin{array}{l}\text { Plasma urea } \\
\text { concentration } \\
\text { (mmol/l) }\end{array}$} & \multicolumn{2}{|c|}{$\begin{array}{l}\text { Urea entry rate } \\
\text { (mg/min) }\end{array}$} & \multicolumn{2}{|c|}{$\begin{array}{c}\text { Urea excretion rate } \\
\text { (mg/min) }\end{array}$} \\
\hline & & 'Model' & Reported & 'Model' & Reported & 'Model' & Reported & 'Model' & Reported \\
\hline $\mathbf{I}$ & $2 \cdot 8$ & $27 \cdot 2$ & $27 \cdot 7$ & $I \cdot I 6$ & $I \cdot 22$ & 3.19 & $2 \cdot 4$ & $1 \cdot 93$ & 0.7 \\
\hline 2 & $3 \cdot 6$ & $27 \cdot 5$ & $30 \cdot 4$ & $x \cdot 48$ & I 88 & 4.09 & $7 \cdot 3$ & $2 \cdot 48$ & $I \cdot O$ \\
\hline 3 and 4 & 13.3 & $3 I \cdot 2$ & 34.8 & $4 \cdot 8 \mathrm{I}$ & 5.39 & 15.11 & 17.9 & $9 \cdot 16$ & 10.0 \\
\hline 5 & $14 \%$ & $31 \cdot 6$ & $29^{\circ} 8$ & $5 \cdot 15$ & $3 \cdot 23$ & $16 \cdot 35$ & 10.0 & 9.92 & 3.9 \\
\hline 6 & $2 \mathrm{I} \cdot 8$ & 344 & $35^{\circ} 0$ & $7 \cdot 16$ & $7 \cdot 54$ & $24 \cdot 76$ & $28 \cdot I$ & 15.01 & 17.4 \\
\hline 7 & $35^{\circ} 0$ & $39 \cdot 8$ & $34 \cdot r$ & $9 \cdot 94$ & $x 1 \cdot 74$ & $39^{\prime} 75$ & $37^{\circ} 4$ & 24.10 & $31 \cdot 8$ \\
\hline
\end{tabular}

and where $R$ is the 'response time', or the carry-over effect, for a change in diet. Here $R$ was assumed to be only $\mathrm{I} d$ and $f_{1}(t)$ was given in $\mathrm{N} / \mathrm{d}$. Equation series 12 are the result of linear interpolation on the coordinates $\left(560, r_{i 7}\right)$ and $\left(700, r_{i 7}\right)$ for each of the estimated daily quantities of $\mathrm{N}$ movement, $r_{i 7} \mathrm{~g} \mathrm{~N} / \mathrm{d}(i=\mathrm{r}, 6,7)$, out of pool 7 for the 'low- $\mathrm{N}$ ' and 'high- $\mathrm{N}$ ' balance models that were used to give the average model in Fig. I.

Steady-state aspects of the seven-pool, variable-coefficient model can now be validated by comparing results predicted by the model with biological measurements other than those used to quantify the model. Such comparisons lead to further validations by simulation of dynamic changes found in independent biological experiments. Critical evaluation of the model's responses to dynamic manipulations could lead to further model refinement.

VALIDATION OF THE SEVEN-POOL MODEL

Prediction of steady-state relationships

Using the model in Fig. $\mathrm{I}$, as modified by equation series $\mathrm{I} 2$, the steady-state pool sizes $q_{i}(\infty), i=1,2, \ldots, 7$ were predicted for a range of $\mathrm{N}$ intakes. This time, physiological measurements such as plasma urea concentration were estimated from the $q_{i}$ 's and compared with actual experimental results.

Animal live weight $(W, \mathrm{~kg})$ was estimated from model output by using the formula:

$$
W=q_{7} \div 20 \text { (Panaretto, }{ }_{1963} \text { ), }
$$

and body fluid volume $(V, 1)$ was then estimated by substitution in the relationship:

$$
V=0.557 W \text { (Packett \& Groves, 1965). }
$$

Rumen fluid volumes were assumed to range between 3 and 51 in sheep consuming diets containing from 3 to $25 \mathrm{~g} \mathrm{~N} / \mathrm{d}$ (in about 500-1000 g dry matter). Plasma urea was related to total $\mathrm{N}$ in pool 6 of the model by a constant scale factor of 0.9 for sheep on this range of dietary $\mathrm{N}$ intakes. The estimate of the scale factor that was used to 
Table 6. The seven-pool model of the dynamics of nitrogen metabolism in sheep consuming forage diets (equation $3(p .154)$ with the matrix in Table 3 modified by equation series 12 (p. $\left.\left.15^{8}\right)\right)$ : predicted values compared with values reported by McIntyre (1970)

\begin{tabular}{|c|c|c|c|c|c|c|c|}
\hline \multirow[b]{2}{*}{ Diet* } & \multirow{2}{*}{$\begin{array}{l}\text { Intake } \\
(\mathrm{g} \mathrm{N} / \mathrm{d})\end{array}$} & \multicolumn{2}{|c|}{$\begin{array}{c}\text { Total urea-N excretion } \\
\qquad(\mathrm{g} \mathrm{N} / \mathrm{d})\end{array}$} & \multicolumn{2}{|c|}{$\begin{array}{l}\text { Rumen ammonia } \\
(\mathrm{mmol} / \mathrm{l})\end{array}$} & \multicolumn{2}{|c|}{$\begin{array}{l}\text { Plasma urea-N } \\
(\mathrm{mmol} / 1)\end{array}$} \\
\hline & & 'Model' & Reported & 'Model' & Reported $\dagger$ & 'Model' & Reported \\
\hline I & $6 \cdot 8$ & 3.60 & $I \cdot 6 I$ & $4 \cdot 2$ & $0-1 \cdot 8$ & $1 \cdot 25$ & 0.98 \\
\hline 2 & ז6.8 & 8.92 & $8 \cdot 87$ & $9 \cdot 6$ & $6.5-10.0$ & $2 \cdot 72$ & 3.45 \\
\hline 3 & 23.5 & $12 \cdot 48$ & $12 \cdot 32$ & $13 \cdot 0$ & $\begin{array}{c}15 \cdot 9-22 \cdot 3 \\
(11 \cdot 7-20 \cdot 5)\end{array}$ & 3.53 & $4 \% 45$ \\
\hline 4 & $37 \cdot 3$ & I $9.8 \mathrm{x}$ & $18 \cdot 52$ & I $8 \cdot 6$ & $14 \cdot 7-21 \cdot 7$ & 4.87 & 475 \\
\hline 5 & $46 \cdot 3$ & $24 \cdot 59$ & $24 \cdot 11$ & $23 \cdot 1$ & $15 \cdot 3-23.5$ & $5 \cdot 5^{8}$ & $4 \cdot 68$ \\
\hline
\end{tabular}

* For details of composition, see McIntyre (1970).

+ Ranges from Fig. 3 of McIntyre (1970), except values in parentheses which are from Nolan \& Leng (1972).

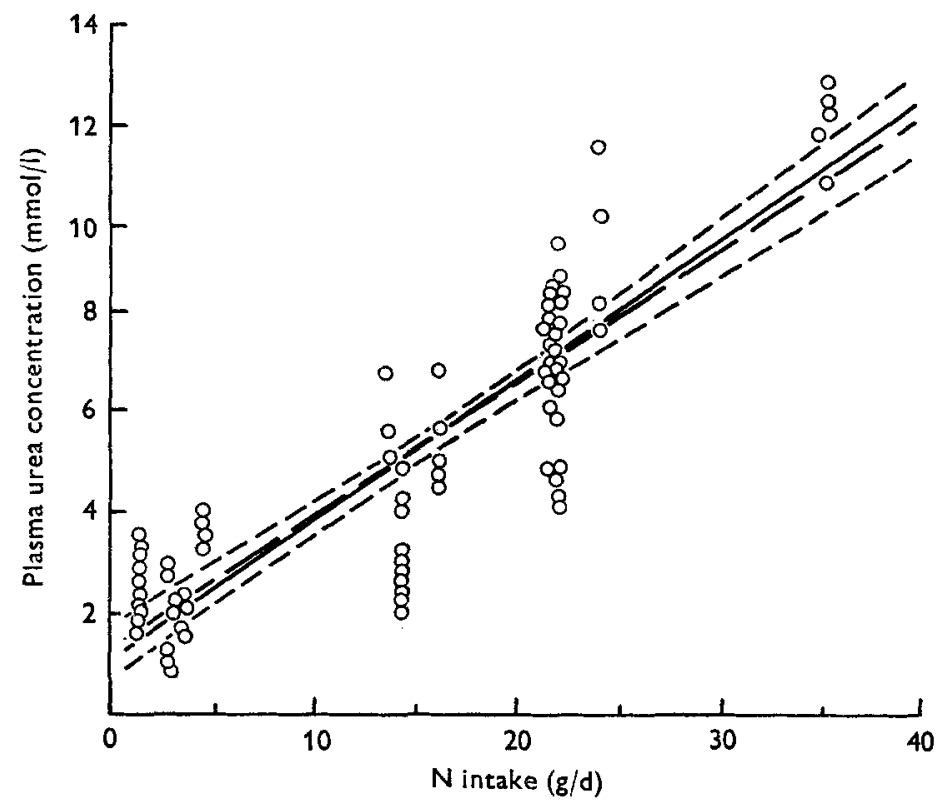

Fig. 2. Relationship between dietary nitrogen intake and plasma urea concentration in sheep consuming forage diets. (-), Predicted by the seven-pool model of the dynamics of $\mathrm{N}$ metabolism, Fig. I, and modified by equation series 12 or 15 (pp. $15^{8}$ and 164 respectively); (- -), the regression line for values reported by Nolan, Cocimano \& Leng (1970); (- - -), $95 \%$ confidence limits for the regression line.

calculate plasma urea concentrations assumed that $42 \%$ of body fluid $\mathrm{N}$ occurred as plasma urea-N.

Predicted steady-state pool sizes were used to calculate values given in Tables 5 and 6 , after applying equations $\mathrm{I} 3$ and 14 together with the assumption that rumen volumes ranged from 3 to $5^{1}$ for the diets considered. These experimental results were independent of those used in postulating and quantifying the model in Fig. I as modified by 


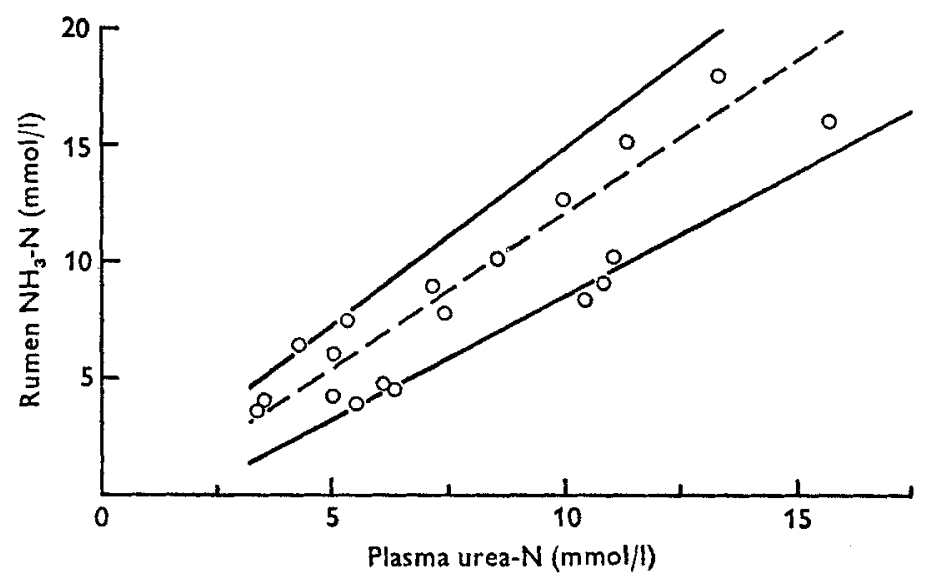

Fig. 3. The relationship between rumen fluid ammonia concentration and plasma urea concentration for sheep consuming forage diets. Values, together with the regression line (- - - ), for prefeeding concentrations of plasma urea and rumen $\mathrm{NH}_{3}$ for sheep on a range of dietary nitrogen intakes (after Egan \& Kellaway, I97 I). Predictions made by the seven-pool model of the dynamics of $\mathrm{N}$ metabolism (-), for a 31 rumen (the upper line) and a 51 rumen (the lower line) show concentration trends with increasing dietary $\mathrm{N}$ intakes.

equation series 12. The inherent linearity of the first six pools of the model is apparent in the regression lines shown in Figs. I-5 of Nolan, Cocimano \& Leng (1970) which are predicted by the model within the $95 \%$ confidence limit for each line. For example, Fig. 2 shows one such relationship between plasma urea concentration and daily dietary $\mathrm{N}$ intake. Fig. 3 (after Egan \& Kellaway, 1971) gives results and the relationship between prefeeding concentrations of rumen $\mathrm{NH}_{3}-\mathrm{N}$ and plasma urea- $\mathrm{N}$ for a range of dietary $\mathrm{N}$ intakes. Assuming either a 3 or 51 rumen volume means that the upper or lower line respectively (Fig. 3 ) is predicted from the model which gives the sizes of $q_{3}, q_{6}$ and $q_{7}$ for the range of forage diets studied by Egan \& Kellaway (1971). These results indicate that the steady-state predictions of the model are now satisfactory.

\section{Simulation of dynamic responses}

The results reported above depend only upon the linearity of the transport of $\mathrm{N}$ between pools $x-6$ and the net losses from them. In effect, this is simply a form of static prediction that can result from any linear model with constant coefficients and with the correct choice of initial pool sizes. If the coefficients used are incorrect, the dynamics of the $\mathrm{N}$ metabolism model will not correspond in any way to the dynamics of $\mathrm{N}$ movement found in living sheep (Berman, 1963 ).

Consequently, the seven-pool model in Fig. I was used to simulate the dynamics of $\mathrm{N}$ metabolism in sheep when inputs of $\mathrm{N}$ were manipulated. The experimental procedures of McIntyre \& Williams (1970) were used to give the input functions for the numerical quadrature of equation 3 with the matrix in Table 3 modified by equation series 12. Thus $f_{1}$ and $f_{6}$ were defined respectively as a food intake of $3.3 \mathrm{~g}$ $\mathrm{N} / \mathrm{d}$ corresponding to ration 3 (McIntyre \& Williams, I970) consumed in $3 \mathrm{~h}$ at the start of each day, zero for the rest of that day, and an intravenous infusion of a total of 


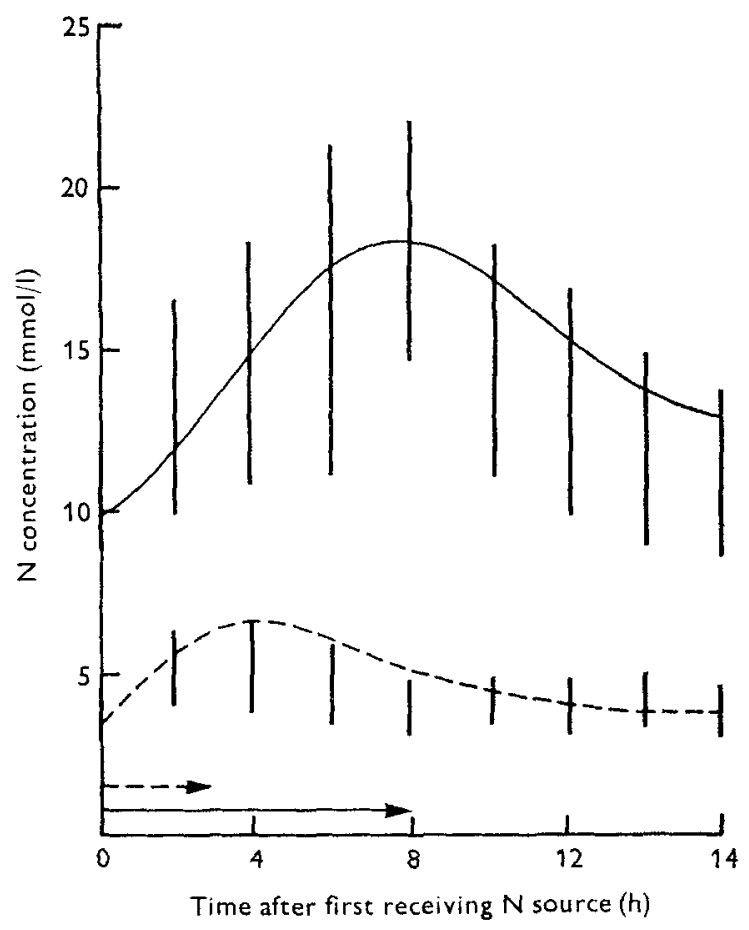

Fig. 4. Daily fluctuations in the concentrations of rumen ammonia-nitrogen (- - - ) and plasma urea-N (-), predicted by the seven-pool model of the dynamics of $\mathrm{N}$ metabolism in sheep consuming forage diets, when $3.3 \mathrm{~g} \mathrm{~N} / \mathrm{d}$ was consumed in the first $3 \mathrm{~h}$ of each day $(-\rightarrow)$ and when $5.5 \mathrm{~g} \mathrm{~N} / \mathrm{d}$ was infused intravenously as urea over the first $8 \mathrm{~h}$ of each day $(\rightarrow)$. The ranges of concentrations represented by vertical bars are those reported by McIntyre \& Williams (r970).

loss of ${ }^{14} \mathrm{C}$ tracer from $\mathrm{L}$-aspartic and L-glutamic acids in rumen fluid. These amino $5.5 \mathrm{~g}$ urea- $\mathrm{N}$ made over the first $8 \mathrm{~h}$ of each day. The remaining five $f_{i}$ were set to zero. Also, the model was adjusted to be in slightly negative $N$ balance to correspond with experimental findings for sheep on the ration, before urea infusion.

This simulation experiment was run over ro $d$ and the results were monitored over the last $8 \mathrm{~d}$. Model predictions of fluctuations in rumen $\mathrm{NH}_{3}-\mathrm{N}$ and plasma urea- $\mathrm{N}$ are compared with experimental results in Fig. 4. Over-all $\mathrm{N}$ balance post-infusion was found to be $+1.7 \mathrm{gN} / \mathrm{d}$ in both the simulation run and the experiment. Thus an independent set of results has validated dynamic aspects of endogenous urea and dietary $\mathrm{N}$ metabolism in the interrelationships between the model's plasma urea- $\mathrm{N}$ and the rumen $N$ pools. Also, these model responses indicate that the positive $\mathrm{N}$ balance in the experiment was not simply a result of urea- $\mathrm{N}$ utilization in the digestive tract (contrast McIntyre \& Williams, r970).

Another test of the model was made by attempting to simulate the disappearance of ${ }^{14} \mathrm{C}$-labelled amino acids from the rumen pool after a single injection of tracer. This utilization of rumen amino acids reflects only the flows of $\mathrm{N}$ out of the rumen amino acid- $\mathrm{N}$ pool, since there is no recycling of the ${ }^{14} \mathrm{C}$ in this instance. 'Model' results are compared in Fig. 5 with the in vitro findings of Portugal \& Sutherland (1966) for the 


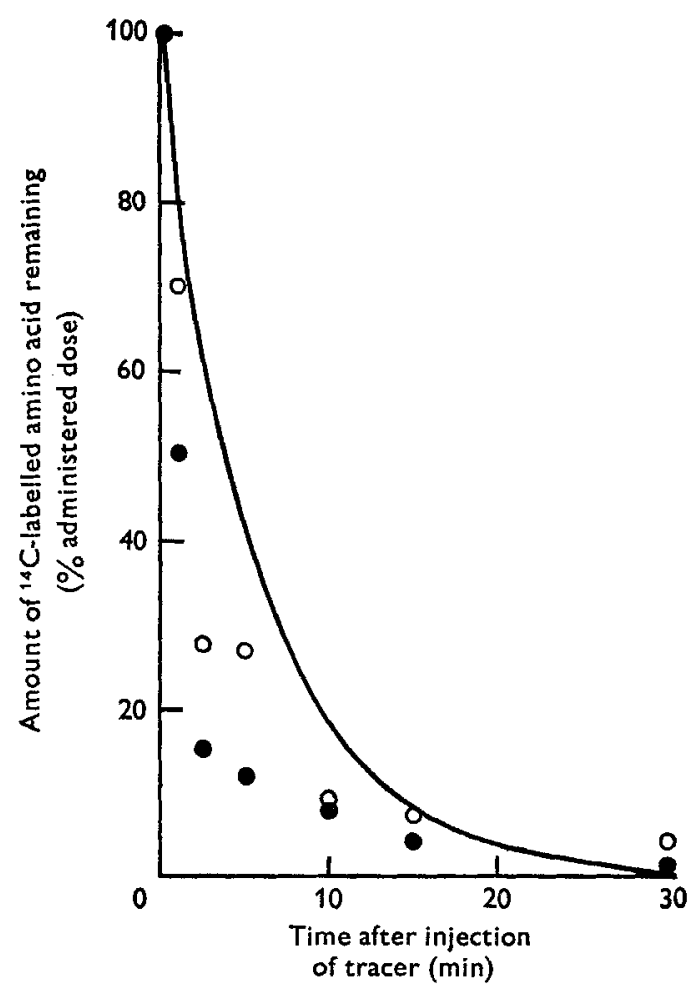

Fig. 5. Comparison of results obtained in vitro (after Portugal \& Sutherland, 1966) for the disappearance of ${ }^{14} \mathrm{C}$-labelled $\mathrm{L}$-glutamic acid $(O)$ and $\mathrm{L}$-aspartic acid $(O)$ from the rumen pool after a single injection of tracer with those obtained for the mean turnover for all amino acids in the rumen from a simulation experiment, using the seven-pool model of the dynamics of nitrogen metabolism in sheep consuming forage diets.

acids are two of the more rapidly metabolized amino acids in the rumen (Lewis \& Emery, 1962). This finding, together with the proportions of more slowly metabolized amino acids that are present in the rumen fluid of sheep (Leibholz, 1969) suggests that the decay curve produced by the seven-pool model is generally consistent with the experimental results shown in Fig. 5 .

\section{Model insufficiencies}

When an injection of tracer into pool 3 was simulated by the model, the peak concentration of tracer in body fluids $\mathrm{N}$, pool 6, occurred at about $\mathrm{r} 8 \mathrm{~h}$. This was not consistent with the peak concentration found at about 4 h by Nolan \& Leng (1972). In this instance, the net flow of $\mathrm{N}$ used did not adequately describe the dynamics of $\mathrm{N}$ transport between pools 6 and 7 of Fig. I, since the relatively large size of pool 7 made it a sink for all incoming tracer.

The net flow, $r_{67}$, from the body tissue $\mathrm{N}$ pool to the body fluids $\mathrm{N}$ pool was not an adequate description of that portion of the animal system. Consequently, rapidly metabolized amino acids were assumed to be involved in a two-way movement of $\mathrm{N}$ between the tissue and body fluid pools. Estimates of these $\mathrm{N}$ movements, that were not used up 
to this stage, increased the flow, $r_{67}$, to $25.25 \mathrm{~g} \mathrm{~N} / \mathrm{d}$ and assumed that there was a new pathway flow, $r_{76}$, of $25.0 \mathrm{~g} \mathrm{~N} / \mathrm{d}$. With the net flow of $\mathrm{N}$ from pool 7 to pool 6 set at $0.25 \mathrm{~g} \mathrm{~N} / \mathrm{d}$, the appearance of ${ }^{15} \mathrm{~N}$ tracer in pool 6 was studied, after a single injection of tracer into pool 3 , for interacting $\mathrm{N}$ flows of $30,25,20,15$ and $\operatorname{rog} \mathrm{N} / \mathrm{d}$. The daily $\mathrm{N}$ transfers $r_{67}(15.25 \mathrm{~g} \mathrm{~N} / \mathrm{d})$ and $r_{76}(15.0 \mathrm{~g} \mathrm{~N} / \mathrm{d})$ produced a curve with a maximum 'enrichment' in pool 6 at almost exactly $4 \mathrm{~h}$. Equation series 12 in this new instance becomes:

$$
\left.\begin{array}{l}
k_{17}=\frac{0 . \mathrm{I}}{\xi}, \\
k_{67}=\frac{\mathrm{I} 5.25}{\xi}, \\
k_{77}=-\frac{\mathrm{I} 9.405}{\xi},
\end{array}\right\}
$$

with $k_{76}={ }_{15} \cdot 0$. The use of these variable rate-coefficients again ensured that the oversimplified tissue $\mathrm{N}$ pool stayed between known bounds.

Clearly, steady-state and certain dynamic aspects of dietary $\mathrm{N}$ metabolism in sheep appear to have been well modelled by the seven-pool system. However the passage of digesta $\mathrm{N}$ between different parts of the digestive tract takes an appreciable time relative to that taken for $\mathbf{N}$ movement through other parts of the body (e.g. in blood). Information concerning time delays (lags) with respect to digesta $\mathrm{N}$ movement was available from Nolan et al. (1976). These results provided appropriate estimates of time delays in the gut which facilitated extension of the seven-pool model to a nine-pool model which includes time delays.

\section{A NINE-POOL LAG MODEL}

\section{Biological considerations and preliminary quantifications}

Nolan et al. (1976) injected $\left({ }^{15} \mathrm{NH}_{4}\right)_{2} \mathrm{SO}_{4}$ into the rumen and caecum of two different sheep and $\left[{ }^{15} \mathrm{~N}\right]$ urea into the blood of a third sheep. The appearance and washout of ${ }^{15} \mathrm{~N}$ was monitored in rumen fluid $\mathrm{NH}_{3}-\mathrm{N}$, rumen bacterial $\mathrm{N}$, caecal supernatant ('r9000 g' supernatant fraction) $\mathrm{NH}_{3}-\mathrm{N}$, caecal debris (' $19000 \mathrm{~g}$ ' residual fraction) $\mathrm{N}$, rectal supernatant $\mathrm{NH}_{3}-\mathrm{N}$, rectal debris $\mathrm{N}$ and plasma urea- $\mathrm{N}$ (Nolan et al. 1976). As a result pool 5 (the 'lower gut' $N$ pool, Fig. I) was divided into small intestinal fluid $N$, caecal fluid $\mathrm{N}$ and rectal fluid $\mathrm{N}$ pools (pools 5, 6 and 7 respectively) (Fig. 6). Pools 6 and 7 in Fig. I became pools 8 and 9 respectively. Only approximate estimates were made initially for the steady-state sizes of the new pools but the total content of the 'lower gut' $\mathrm{N}$ pools had to be the same as for the seven-pool model, that is, $2.5 \mathrm{~g} \mathrm{~N}$. Also the sum of $\mathrm{N}$ flows to and from the new pools was initially assumed to be the same as for the seven-pool model.

It was argued that the small intestine $\mathrm{N}$ pool would have a high level of interaction with the body fluids pool, and that the caecum (colon) would have a more appreciable net loss of $\mathrm{N}$ than the remainder of the large intestine. The small intestine pool was assumed to contain $0.8 \mathrm{~g} \mathrm{~N}$, the caecum $\mathrm{I} \cdot \mathrm{I} \mathrm{g} \mathrm{N}$ and the rectum $0.6 \mathrm{~g} \mathrm{~N}$. Using the times of initial appearance of water-soluble, indigestible marker, ${ }^{51} \mathrm{Cr}$ EDTA, at the caecum 
Table 7. Steady-state flows ( $g$ nitrogen/d) between the pools of the nine-pool lag model of the dynamics of $N$ metabolism in sheep consuming forage diets

(Delayed transfers $(\mathrm{g} \mathrm{N} / \mathrm{d}$ ) are given in italics and the delays (min) are given as subscripts. Values not included are $\left.0^{\circ} \mathrm{O}\right)$.

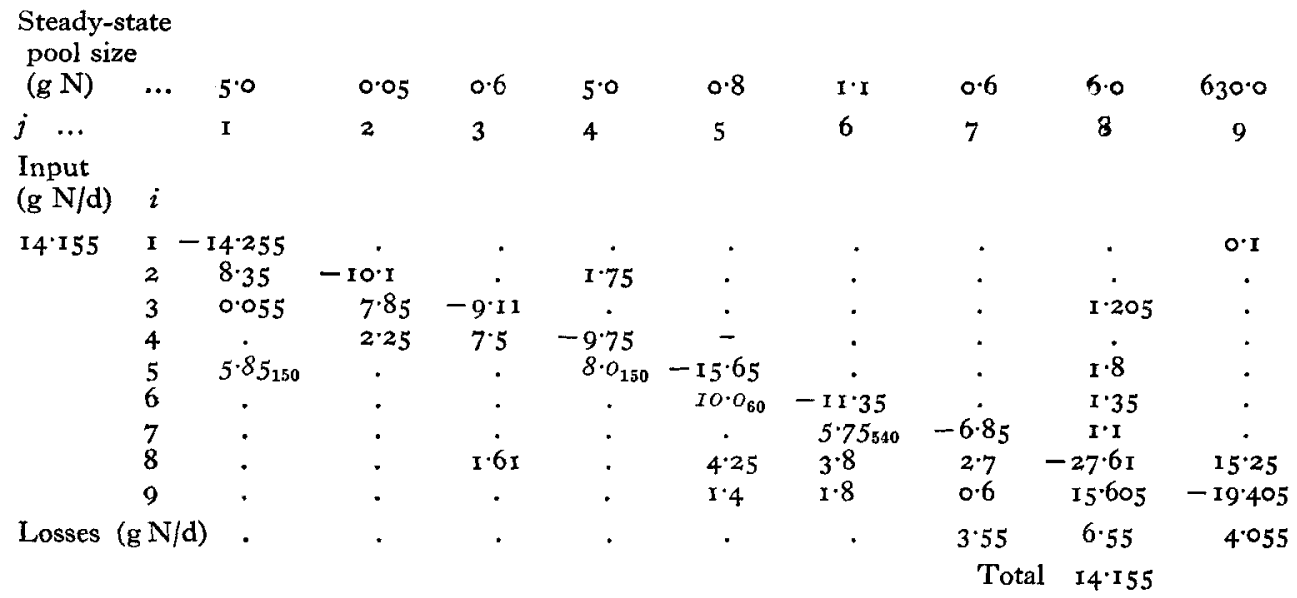

and the rectum gave estimates of the delays, $D_{51}, D_{54}, D_{65}$ and $D_{67}$, in the movement of water from pools $I$ and 4 to pool 5 (a guess), from pool 5 to pool 6 (by difference) and from pool 6 to pool 7 (by difference), respectively.

Table 7 gives the estimated steady-state daily flows of $\mathrm{N}$ between the nine pools of the initial lag model, together with the assumed pool sizes and the time delays. It must be noted that the flow of $\mathrm{N}$ from pool 3 to the tissue $\mathrm{N}$ pool has been re-routed through the body fluids pool to make this transfer of $\mathrm{N}$ biologically more meaningful.

The effect of the time delays on the mathematical description (equation series 2 ) of the dynamics of $\mathrm{N}$ metabolism in sheep is that transfers of $\mathrm{N}$ such as $r_{51}$ and $r_{54}$ arrive at their destination, pool 5 , delayed by times $D_{51}$ and $D_{54}$, respectively. That is, the instantaneous rate of influx of $\mathrm{N}$ into pool 5 from pool $\mathrm{r}$, for example, is $k_{51} q_{1}\left(t-D_{51}\right)$ instead of $k_{51} q_{1}(t)$.

\section{Mathematical considerations}

The difference-differential equation series that now describes the dynamics of $\mathrm{N}$ metabolism in sheep is:

$$
\frac{d q_{i}(t)}{d t}=\sum_{j=1}^{n}\left(a_{i j} q_{j}(t)+b_{i j} q_{j}\left(t-D_{i j}\right)\right)+f_{i}(t) \quad(i=1,2,3, \ldots, n),
$$

where $\left(a_{i j}+b_{i j}\right) \equiv k_{i j}$ and $a_{i j}=0$ for all $\mathrm{N}$ transfers delayed by time $D_{i j}, q_{i}(t)$ is the quantity of $\mathrm{N}$ in pool $i$ with $n=9$ for the model in Fig. 6 and where the $f_{i}$ are the $\mathrm{N}$ inputs. Rate constants $a_{i j}$ and $b_{i j}$ can be calculated from Table 7 by dividing the entries in each column by the steady-state pool size corresponding to that column, while the $D_{i j}(d)$ can be deduced by dividing the delays ( $\mathrm{min}$ ) given in Table 7 by 1440.

Time lags, such as those brought about by the passage of digesta in sheep, cannot be 


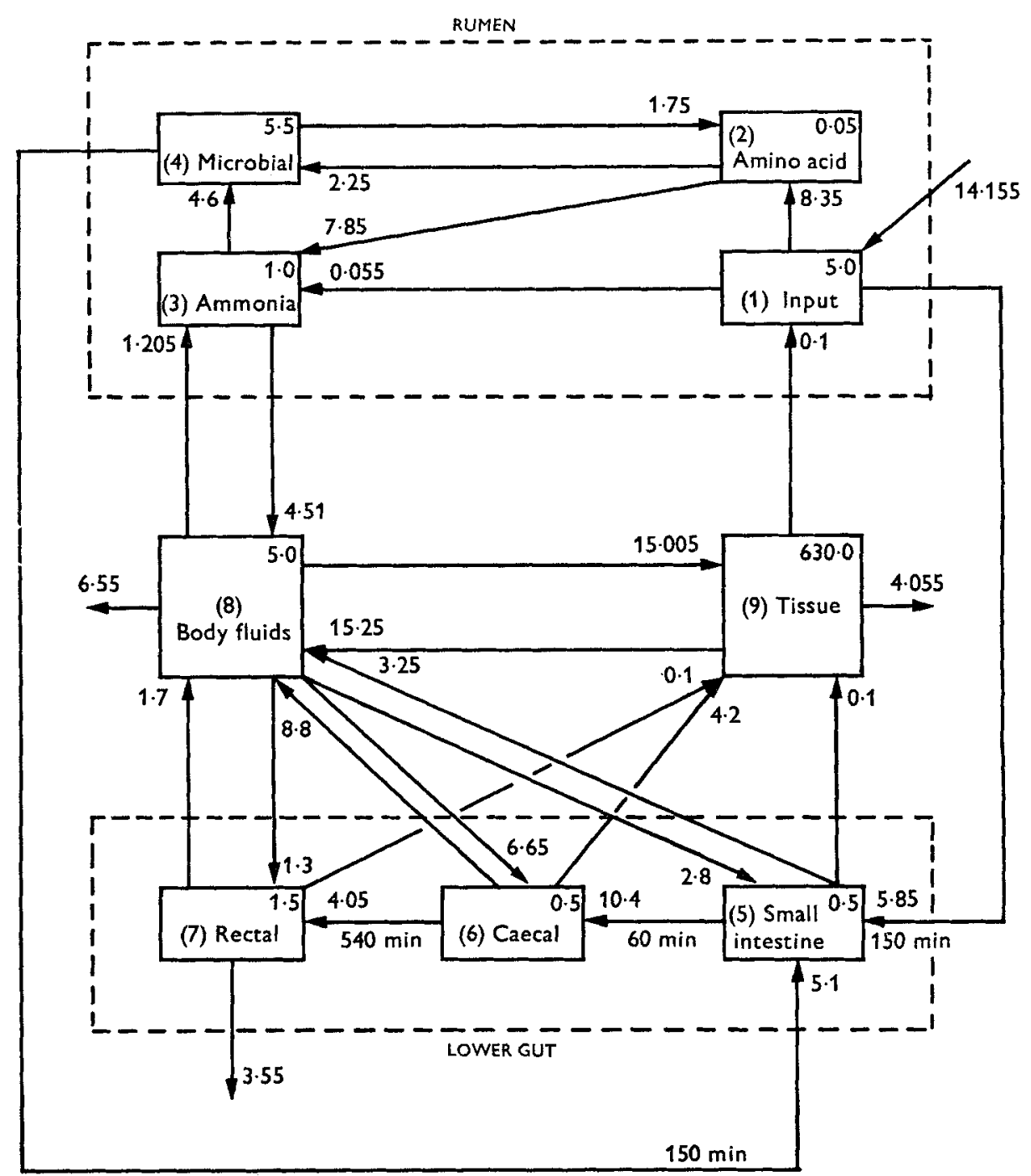

Fig. 6. The nine-pool lag model of the dynamics of nitrogen metabolism in sheep consuming forage diets, with values for daily $\mathrm{N}$ transfers $(\mathrm{g} \mathrm{N} / \mathrm{d}$ ) and time lags (min) for a dietary $\mathrm{N}$ intake of $14^{\cdot}+55 \mathrm{~g} \mathrm{~N} / \mathrm{d}$. Pool sizes ( $\mathrm{g} \mathrm{N}$ ) for this diet are shown in the top right-hand corner of each box.

treated here simply by inserting extra pools as suggested by Berman, Weiss \& Shahn (1962). The number of extra pools needed to simulate a delay depends on the time increment, $\delta t$, used to generate numerical solutions of the resulting equations and on the size of the extra pools used. If the extra pools are to define the estimated time delays, then in a finite difference numerical scheme there must be $D_{i j} \div \delta t$ extra small pools for each delay $D_{i j}$. However, theoretically, a system of instantaneously linked pools can never produce real delays, since tracer introduced at any point in the system appears instantaneously at all points in the system. 
If any $a_{i j}$ and $b_{i j}$ in equation series $\mathrm{I} 6$ is a function of any $q_{i}(t)$ in the system (cf. Mazanov, $1973 a, b$ ), then that system of equations becomes non-linear. For a linear system the parameters $a_{i j}, b_{i j}$ must be zero, constant, or functions of time and environmental conditions. In this paper, non-linear systems are not considered because their mathematical models can become unstable with increasing complexity (more pools and flows between pools) or when time delays are introduced (Hale, 1971; May, 1973). Also, Mazanov (1976) has proved that linear compartment models of open biological systems are stable independently of complexity or the duration of any time delays, thus ensuring that all $\lambda$, eigenvalues of such systems have negative real parts.

Again, since the nine-pool lag model is clearly more complex than the seven-pool model, numerical solutions were again generated on a digital computer to study the dynamic responses of the model. When tracer studies were to be simulated, the steadystate pool sizes and dietary $\mathrm{N}$ input were constant and it was therefore possible to use constant-coefficient, lag-differential equations to simulate such experiments. However, when dietary $\mathrm{N}$ intakes were varied, the recycling and losses of $\mathrm{N}$ from the oversimplified tissue $\mathrm{N}$ pool in the above model again had to be varied by using equations:

$$
\left.\begin{array}{l}
a_{19}=\frac{0 \cdot \mathrm{I}}{\xi}, \\
a_{89}=\frac{\mathrm{I} 5 \cdot 25}{\xi}, \\
a_{99}=-\frac{19 \cdot 405}{\xi},
\end{array}\right\}
$$

where $\xi$ is the same as for equation series 12 (p. 158$)$ and $\mathrm{I}_{5}$ (p. 164).

\section{Model refinement}

Initial experimental enrichments of ${ }^{15} \mathrm{~N}$ in pools 3,6 and 8 were estimated from the curves of Nolan et al. (1976) as 3, I0, and I.7 atoms/100 atoms excess respectively. With the size of injection of tracer set to the quantity of ${ }^{15} \mathrm{~N}$ in that pool, and the rest of the pools set to zero at time zero, numerical output from the model was converted to a measure of atoms/100 atoms ${ }^{15} \mathrm{~N}$ excess in each pool of the model so that the results could be compared with available data.

Three separate solutions of equation series 16 , with coefficients and delays calculated from Table 7 , were generated. This resulted in three sets of data giving a decay curve and either build-up and decay curves in each. Curves corresponding to results of available tracer experiments of Nolan et al. (1976) were compared with these biological results. The comparisons indicated that for the model defined by Table 7 , the rate of flow of ${ }^{15} \mathrm{~N}$ from pool 3 after an intraruminal injection of tracer was far too high. Also, not nearly enough ${ }^{15} \mathrm{~N}$ reached the caecum, the rectum or plasma urea. For an intracaecal injection of tracer, not enough ${ }^{15} \mathrm{~N}$ left the caecum and far too much ${ }^{15} \mathrm{~N}$ reached pools 3 and 8 and also, after the time delay, the rectum. An amount of tracer which was 
1000 times too great was reaching the rectum down the alimentary tract. An intravenous injection of tracer into pool 8 indicated that too much label moved from pool 8 to pools 3 and 7 while too little reached pool 6.

These interpretations of simulation results could easily have to be changed, since the dynamic nature of the flows in the model is so important that a very slight alteration of even a single $r_{i j}$ could influence the shapes of the solution curves produced by the model to a great extent. However, if one $r_{i j}$ is changed then the whole model must be rebalanced so that all influxes exactly equal the total effux for any pool and for the model as a whole. After each such change all three sets of solution curves were regenerated with the same set of parameters and again compared with experimental results. (Also, enrichment calculations depend on assumed steady-state pool sizes which may have been inaccurately estimated.)

Successive iteration through the above steps of modification of the flows of $\mathrm{N}, \boldsymbol{r}_{i j}$, in the model, balancing each pool and the model as a whole, and then again generating numerical solutions eventually gave three sets of curves which could not be improved further by changing the $r_{i j}$. At this stage, model pool sizes were altered to give slightly better agreement between model output and the experimental results of Nolan et al. $(1976)$.

\section{A model validation}

The final, refined flows and pool sizes for the nine-pool lag model of the dynamics of $\mathrm{N}$ metabolism in sheep given forage diets are shown in Fig. 6. Solutions produced by this final model are shown in Figs. 7, 8 and 9 together with the results of three tracer experiments done by Nolanetal.(1976). It is important to note again that the same set of parameters was used to simulate all three tracer experiments.

Optimal curves for individual sets of data could have been generated by manipulation of artificially selected model parameters, with or without re-balancing the model $\mathrm{N}$ flows. However, such manipulations would have been inconsistent with the intention of developing a model for $\mathrm{N}$ metabolism in sheep and such an approach, most probably, would not result in a set of biologically feasible coefficients. Also, individual optimizations were not really necessary, since the character of the simulated results shown in Figs. 7-9 is consistent with experimental findings and is within the range of differences found between animals. The dynamics of the nine-pool model with lags have thus been validated according to the criteria of Berman ( 1963 ), and therefore the parameters used are characteristic of the animal metabolism system under consideration.

In addition, since equation series 16 as modified by equation series 17 are linear for the nine-pool system, all the steady-state predictions that were made for the seven-pool model can be made equally well by the nine-pool model with lags.

Assuming that protected protein, which escapes rumen fermentation is effectively an input, $f_{5}$, of $\mathrm{N}$ directly into pool 5 and that dietary urea $\mathrm{N}$ is an input into pool 3 , the rumen $\mathrm{NH}_{3}-\mathrm{N}$ pool, the effects of different compositions of dietary $\mathrm{N}$ intakes could be simulated by the nine-pool lag model. In this instance $f_{1}$ would have to be replaced by $\left(f_{1}+f_{3}+f_{5}\right)$ in the calculation of $\xi$ for equation series 17 . Preliminary simulation studies currently in progress suggest that the nine-pool lag model's predictions compare 


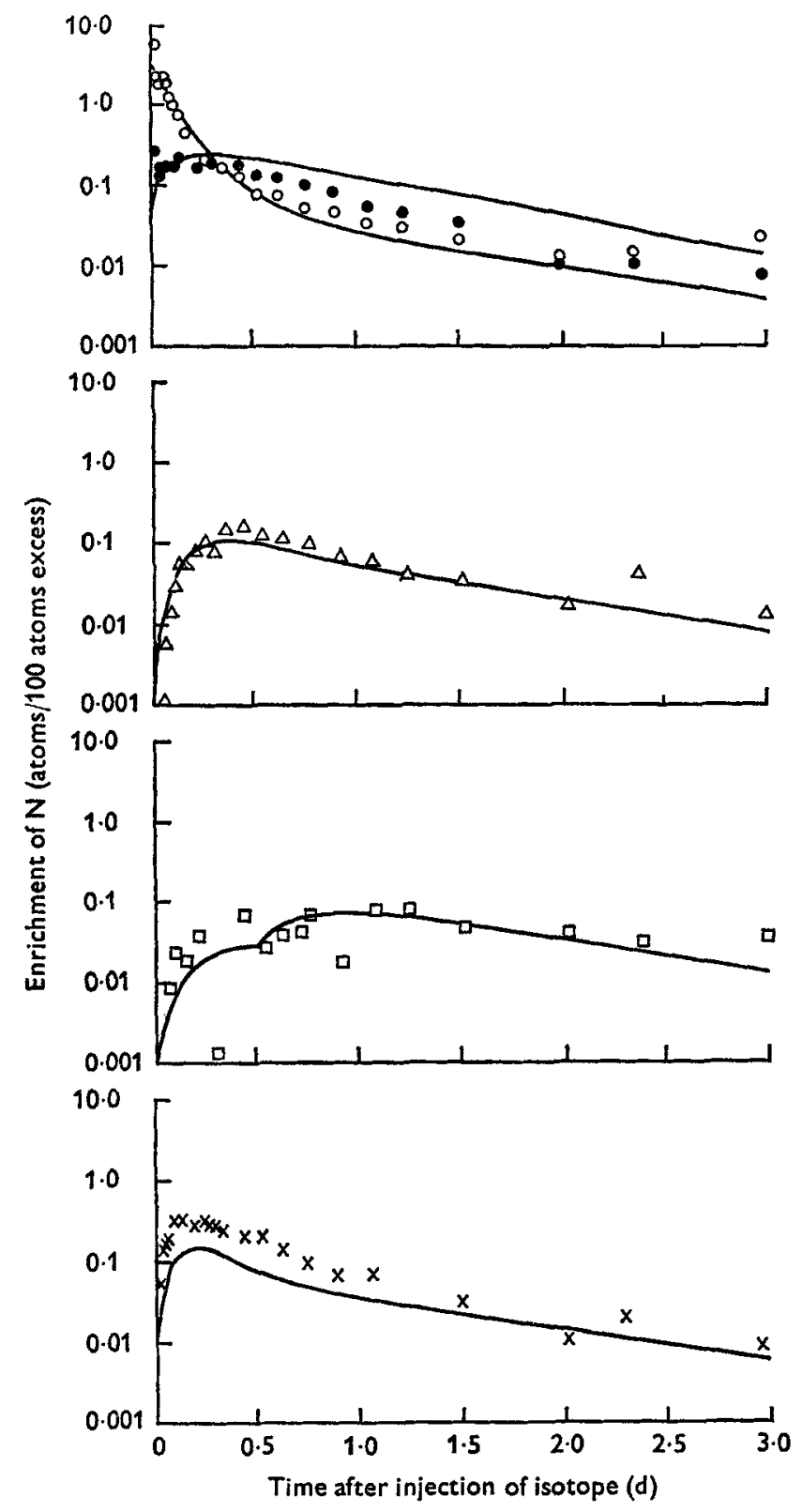

Fig. 7. Enrichments of rumen ammonia-nitrogen $(O)$, rumen bacteria $\mathrm{N}(O)$, caecal $\mathrm{NH}_{3}$ $\mathrm{N}(\triangle)$, rectal $\mathrm{NH}_{3}-\mathrm{N}(\square)$, plasma urea- $\mathrm{N}(\times)$ with time after a single injection of $\left({ }^{15} \mathrm{NH}_{3}\right)_{2} \mathrm{SO}_{4}$ into the rumen of a sheep (after Nolan, Norton \& Leng, 1976). ( - ), Simulated curves produced by the nine-pool lag model of the dynamics of $\mathrm{N}$ metabolism of sheep consuming forage diets (Fig. 6). 


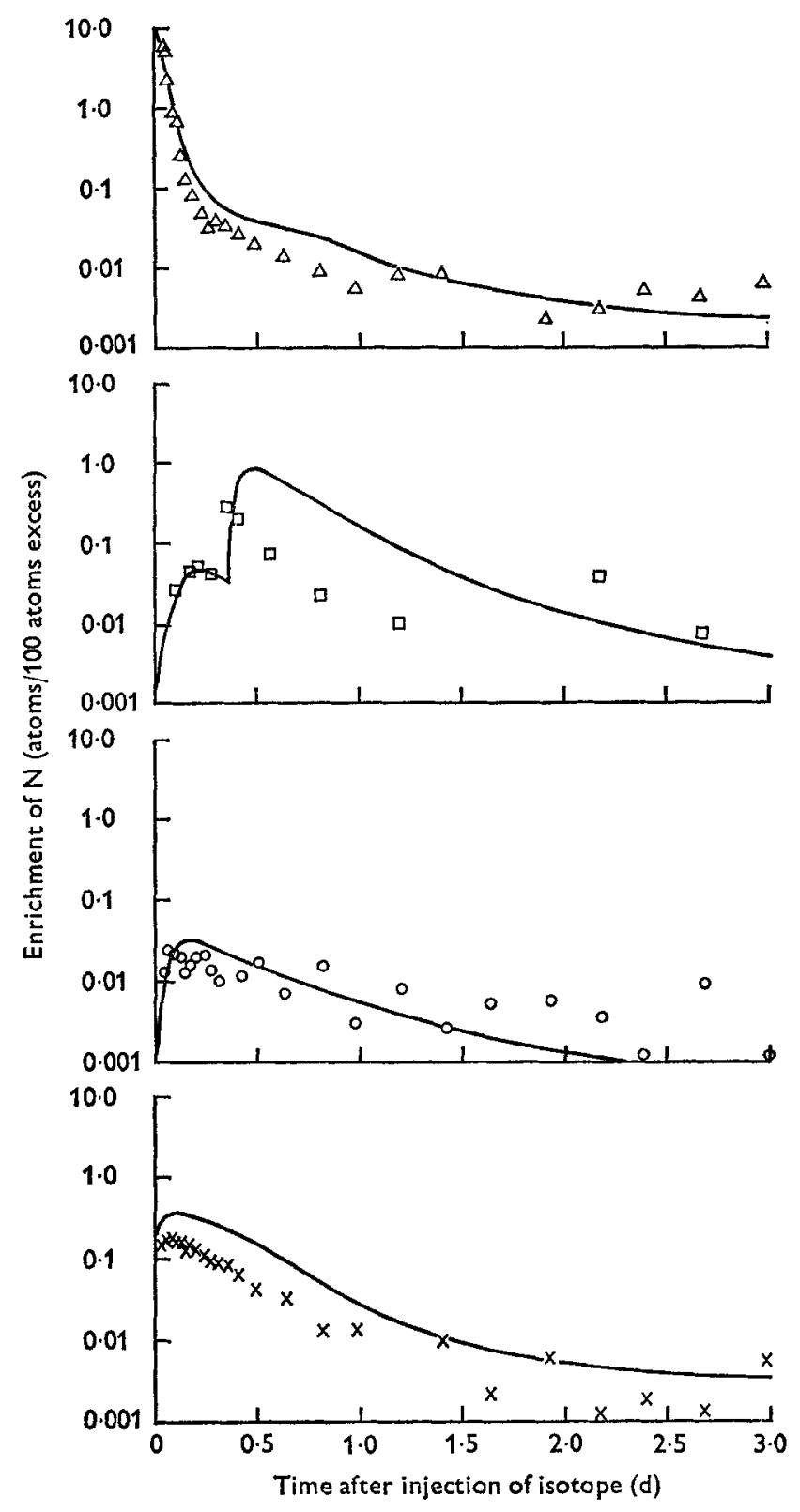

Fig. 8. Enrichments of caecal ammonia-nitrogen $(\triangle)$, faecal $\mathrm{NH}_{3}-\mathrm{N}(\square)$, rumen $\mathrm{NH}_{3}-\mathrm{N}(O)$, plasma urea-N $(x)$, with time after a single injection of $\left({ }^{15} \mathrm{NH}_{4}\right)_{2} \mathrm{SO}_{4}$ into the caecum of a sheep (after Nolan, Norton \& Leng, 1976). ( $\longrightarrow$ ), Simulated curves produced by the ninepool lag model of the dynamics of $\mathrm{N}$ metabolism of sheep consuming forage diets (Fig. 6 ). 
Vol. 35

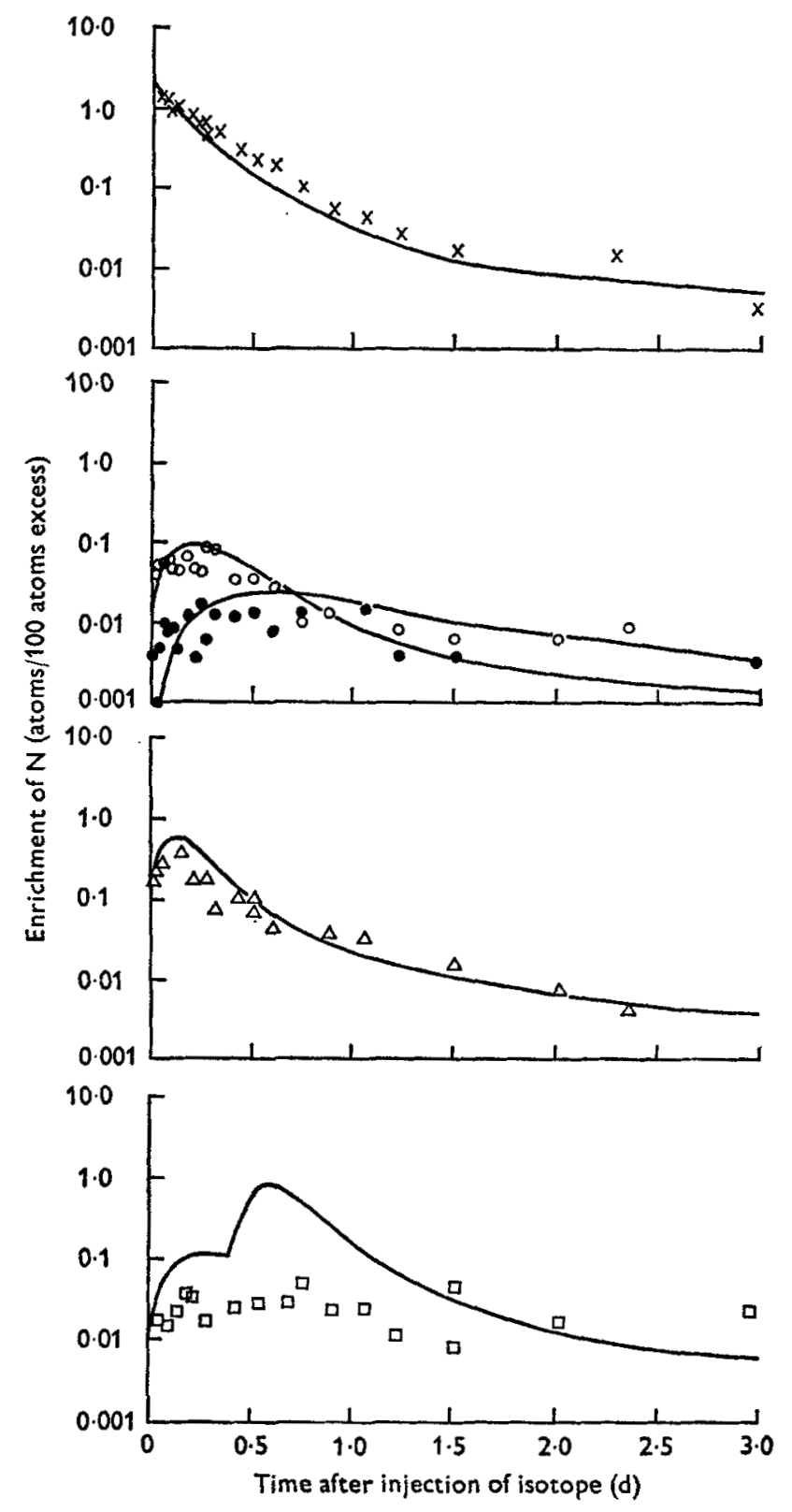

Fig. 9. Enrichments of plasma urea-nitrogen $(x)$, rumen ammonia- $N(O)$, rumen bacterial $N$ (O), caecal $\mathrm{NH}_{3}-\mathrm{N}(\triangle)$ rectal $\mathrm{NH}_{3}-\mathrm{N}(\square)$ with time after a single injection of [ $\left.{ }^{15} \mathrm{~N}\right]$ urea into the blood of a sheep (after Nolan, Norton \& Leng, 1976). $(\stackrel{一}{\longrightarrow}$ ), Simulated curves produced by the nine-pool lag model of the dynamics of $\mathrm{N}$ metabolism of sheep consuming forage diets (Fig. 6). 
favourably with available data and therefore such computer studies should serve as further validations of this model in due course.

However, it must be acknowledged here that the lower curves in Figs. 7-9 are significantly different from the experimental values shown in these figures. This is a direct consequence of the over-simplification of the body fluid $\mathrm{N}$ pool and the flows assumed for $\mathrm{N}$ transfers from pool 6 to pools 7 and 8 in Fig. 6.

\section{DISCUSSION}

Model development can be approached in many ways. The present study was based on the following principles. First, to be a useful addition to biological experimentation, the mathematical argument must be based on an understanding of the biological nature of the processes involved in the model; the alternative is to describe the processes by statistical or probability arguments based on experimental results. Secondly, model development is facilitated by the construction of the simplest model that produces output which can be validated. The model can then be added to as required. Each addition to the model must improve its ability to simulate the animal system it represents. When improvement does not follow an increase in complexity of the model, the effect of the most recent modification can be studied further. By contrast, if an initially complex model fails to simulate correctly, it is difficult to find the part(s) of the model at fault. These beliefs are illustrated in the present studies by the development of the wholeanimal model of the $\mathrm{N}$ cycle in sheep.

In the first instance, the twenty-five-pool flow model of Nolan \& Leng (r972) was simplified to a conceptual seven-pool model by amalgamation of various parts of the more complex model. Then, two sets of quantitative results for sheep given high and low dietary $\mathrm{N}$ intakes were applied to this conceptual model and small adjustments of data were made to give the 'high- $N$ ' and 'low- $N$ ' balanced models.

A comparison of the rate-constants for corresponding processes for the 'high- $N$ ' and 'low- $\mathrm{N}$ ' models indicated that these were, in general, of the same order of magnitude. It was thus reasonable to suppose that these rate-constants would apply to $\mathrm{N}$-balance situations under other dietary $\mathrm{N}$ intakes. Any appreciable differences in some of the coefficients may have resulted from over-simplifications of the biological nature of the processes involved. To the extent that these differences occurred, rateconstants were not adequate definitions of these processes in the model.

Actual urea metabolism results of Nolan et al. (1970) for urea and $\mathrm{NH}_{3}$ metabolism, obtained from studies of animals in the range of $N$ intakes and physiological conditions considered in this paper, were compared with model output. This comparison indicated that the assumption of linearity in models of $\mathrm{N}$ metabolism in sheep was compatible with these biological results. Dietary $\mathrm{N}$ was, therefore, assumed to be the only limiting factor in all our models. To that end, the dynamic processes of $\mathrm{N}$ metabolism in sheep are adequately described by first-order kinetics. This hypothesis is supported by the good agreement obtained between model output and experimental results over a wide range of $\mathrm{N}$ intakes in forage diets.

First-order kinetic models have adequately simulated relationships between $\mathrm{N}$ 
intake and $\mathrm{N}$ metabolism as $\mathrm{NH}_{3}$ and urea, and probably also as amino acids under the conditions of the present study.

Generalization of this concept may also hold, with new sets of parameters, for animals in different physiological conditions or beyond the dietary limits used to construct this model. However, a gross change in the proportions of absorbed amino acids could markedly alter the rate-coefficients for tissue protein and urea synthesis in the animals considered in this study. Such a gross change in the proportions of absorbed amino acids is very unlikely in animals given forage diets. With these provisos, it appears that concentration or quantity of substrate exerts a primary influence on the quantities of $\mathrm{N}$ transferred in the body. Obviously hormonal and neural factors must have particular involvements as coordinators in the maintenance of over-all homoeostasis.

When a number of steady-state models for a range of diets become available and are compared, the nature of the variation, if any, of the coefficients in the matrix, $K$, can be studied and a suitable variable-coefficient model can be constructed (Mazanov, I973a). Variable-coefficient models were used previously and these models would also be needed to simulate the dynamics of glucose metabolism in sheep, since pool sizes may remain constant while glucose entry rates vary from 54 to $100 \mathrm{mg} / \mathrm{min}$ (Judson \& Leng, 1973; Steel \& Leng, 1973).

Time delays exist in the animal and must be allowed for explicitly. Further refinement of the nine-pool lag model can occur only when more results from animal experiments become available. Such refined models should produce better simulations and give better fits to tracer dilution curves such as those of Nolan et al. (1976).

The present study clearly illustrates our belief that whole-animal models should be considered and that animals should be studied as complete entities. A maximum number of estimates of independently measured processes may then be compared simultaneously with predicted results. In this way the strengths and weaknesses both of the models and of the level of understanding of metabolic processes are highlighted and research programmes expedited.

The authors acknowledge the financial support of this and related projects by the Rural Credits Development Fund, the Australian Wool Research Committee and the Australian Meat Research Committee. Professor R. A. Leng, Dr N.W. Taylor, Dr T.M. Sutherland, Dr E. N. Dancer and Dr I.D. Hume of The University of New England are thanked for valuable discussions.

\section{REFERENCES}

Benyon, P. R. (1968). Simulation 11, 219.

Berman, M. (1963). F. theor. Biol. 4, 229.

Berman, M. (1969). FEBS Lett. 2, Suppl. $\mathrm{S}_{5} 6$.

Berman, M. \& Schoenfeld, R. (1956). F. appl. Phys, 27, 1361.

Berman, M., Weiss, M. F. \& Shahn, E. (1962). Biophys. F. 2, 289.

Cocimano, M. R. \& Leng, R. A. (r967). Br. F. Nutr. 2r, 353 .

Cooper, G. J. (1969). FEBS Lett. 2, Suppl. S22.

Downes, A. M., Reis, E. J., Sharry, L. F. \& Tunks, D. A. (1970). Aust. F. biol. Sci. 23, 1077.

Egan, A. R. \& Kellaway, R. C. (197I). Br. F. Nutr. 26, 335.

Gill, W. (195 I). Proc. Camb. phil. Soc. math. phys. Sci. 47, 96.

Hale, J. (1971). Functional Differential Equations. New York: Springer-Verlag. 
Hearon, J. Z. (1963). Ann. N.Y. Acad. Sci. 108, 36.

Judson, G. J. \& Leng, R. A. (1973). Br. F. Nutr. 29, 156.

Leibholz, J. (1969). F. Anim. Sci. 29, 628.

Lewis, T. R. \& Emery, R. S. (I962). ¥. Dairy Sci. 45, 765.

McDonald, P., Edwards, R. A. \& Greenhalgh, J. F.D. (1973). Animal Nutrition, 2nd ed., p. 432. Edinburgh: Oliver \& Boyd.

McIntyre, K. H. (1970). Aust. F. agric. Res. 2r, 5or.

McIntyre, K. H. \& Williams, V. J. (1970). Aust. F. agric. Res. 21, 95.

Mancini, P. \& Pilo, A. (1970). Comput. biomed. Res. 3, I.

May, R. M. (1973). Stability and Complexity in Model Ecosystems. Princeton, USA: Princeton University Press.

Mazanov, A. (1973a). F. envir. Mgmt I, 229.

Mazanov, A. (1973 b). Aust. Comput. F. 5, 74.

Mazanov, A. (1976). F. theor. Biol. (In the Press.)

Muntz, Ch. (1936). Uber dem Approximationssatz von Weierstrass Mathematische Abhandlungen. Berlin: Springer-Verlag.

Nolan, J. V. (197I). Dynamics of protein metabolism in sheep. PhD Thesis, The University of New England, Australia.

Nolan, J. V., Cocimano, M, R. \& Leng, R. A. (I g7o). Proc. Aust. Soc. Anim. Prod. 8, 22.

Nolan, J. V. \& Leng, R. A. (1972). Br. F. Nutr. 27, I77.

Nolan, J. V. Norton, B. W. \& Leng, R. A. (1976). Br. F. Nutr. 35, 127.

Packett, E. V. \& Groves, T. D. D. (1965). F. Anim. Sci. 24, 34I

Panaretto, B. A. (1963). Aust. F. agric. Res. r3, 320.

Portugal, A. V. \& Sutherland, T. M. (1 966). Nature, Lond. 209, 5 ro.

Ralston, A. (1960). In Mathematical Methods for Digital Computers, vol. 1, p. 95 [A. Ralston and H. S. Wilf, editors]. New York: John Wiley \& Sons Inc.

Ralston, A. (1965). A First Course in Numerical Analysis, p. 200. Tokyo: McGraw-Hill-Kogakusha.

Rescigno, A. \& Segre, G. (1966). Drug and Tracer Kinetics. Waltham: Blaisedell.

Romanelli, M. J. (1960). In Mathematical Methods for Digital Computers, vol. I, p. I ro [A. Ralston and H. S. Wilf, editors]. New York: John Wiley \& Sons Inc.

Runge, C. (1895). Math. Annln 46, I67.

Shipley, R. A. \& Clarke, R. E. (1972). Tracer Methods for In Vitro Kinetics. Theory and Applications. London: Academic Press.

Steel, J. W. \& Leng, R. A. (1973). Br. F. Nutr. 30, 45 I.

Wylie, C. R. Jr (1966). Advanced Engineering Mathematics, p. 477. Tokyo: Kogakusha. 